\title{
The Site Effect on PAHs Formation in HACA-based Mass Growth Process
}

\author{
Peng Liu ${ }^{\mathrm{a}^{*}}$, Zepeng Li ${ }^{\mathrm{a}}$, Anthony Bennett ${ }^{\mathrm{a}}, \mathrm{He} \mathrm{Lin}^{\mathrm{b}}{ }^{*}, \mathrm{~S}$. Mani, Sarathy ${ }^{\mathrm{a}}$, William L. Roberts ${ }^{\mathrm{a}}$ \\ ${ }^{a}$ King Abdullah University of Science and Technology (KAUST), Clean Combustion Research Center, Thuwal 23955- \\ 6900, Saudi Arabia \\ ${ }^{b}$ Key Laboratory for Power Machinery and Engineering of Ministry of Education, School of Mechanical Engineering, \\ Shanghai Jiao Tong University, Shanghai 200240, China
}

\begin{abstract}
Hydrogen-abstraction/acetylene-addition (HACA) pathway has long been postulated as the dominant pathway for the formation of polycyclic aromatic hydrocarbons (PAHs) and the surface growth of soot. In this study, the site effect on PAH formation following HACA pathway is systematically investigated using density functional theory, transition state theory and premixed flame kinetic modeling. The entire reaction network includes 186 elementary reactions, starting from benzene to pyrene. Analysis of the potential energy surface and kinetic parameters show that $\mathrm{H}$ abstraction and $\mathrm{C}_{2} \mathrm{H}_{2}$ addition reactions are greatly sensitive to the site position (ortho-, meta- and para-position) relative to the existing $\mathrm{C}_{2} \mathrm{H}$ chain and surface site type (zig-zag, free-edge and armchair). Specifically, $\mathrm{H}$ abstraction and $\mathrm{C}_{2} \mathrm{H}_{2}$ addition reactions on the ortho-position and armchair surface site are kinetically unsupported due to the relatively high energy barrier and orientation hindrance effect compared with other site options. Therefore, the formation of a new benzene ring by the addition of the second $\mathrm{C}_{2} \mathrm{H}_{2}$ molecule on the ortho-position (e.g., 1-ethynylnaphthalene $+\mathrm{C}_{2} \mathrm{H}_{2} \rightarrow$ phenanthrene) or the first $\mathrm{C}_{2} \mathrm{H}_{2}$ molecule on the armchair surface site (e.g., phenanthrene $+\mathrm{C}_{2} \mathrm{H}_{2} \rightarrow$ pyrene) is unlikely, as demonstrated by PAH simulations in a premixed $\mathrm{C}_{2} \mathrm{H}_{4} / \mathrm{O}_{2} / \mathrm{N}_{2}$ sooting flame. The yield distribution of various reaction products has been investigated using a 0-D reactor, where the combustion conditions are taken from experimental data. The results show that the dominant products are di-substituted PAHs in benzene-naphthalene reaction system and PAHs with 5-membered ring structures in larger PAHs reaction systems. The existence of abundant PAHs with 5-membered rings contributes to clarifying the PAHs signal detected using laser induced fluorescence technology. Additionally, the observed sequence of mass peaks at intervals of mass number 26 in $\mathrm{C}_{2} \mathrm{H}_{2} / \mathrm{C}_{2} \mathrm{H}_{4}$ pyrolysis is reasonably explained by the HACA pathway with considering site effect.
\end{abstract}

Keywords: PAH, site effect, soot, kinetic, DFT. 


\section{Introduction}

The science of polycyclic aromatic hydrocarbons (PAHs) plays a crucial role in our life. Evidence shows that PAH molecules attached to ultrafine particle surfaces can bond to critical targets in DNA molecules, and the PAH-DNA adducts increase the risk of cancer in humans, especially lung and skin cancers $[1,2]$. In addition, studies on PAH formation are motivated by soot pollution in megacities, as PAHs are regarded as the precursors to soot formation in flames [3-11]. On the other hand, PAHs are widely used as modelling molecules of 2D graphene-type materials $[12,13]$, which present excellent optical, mechanical and electrical characteristic. Exploring the formation pathway of PAHs is also beneficial in developing chemically modified 2D graphenetype materials [14]. Furthermore, understanding the evolution of PAHs contributes to revealing the origin and evolution of our universe, especially the formation of galaxies as PAHs are major dust components in the interstellar medium $[15,16]$.

PAHs are mainly formed from the incomplete combustion of hydrocarbons, and the mass growth process is chemically driven by elementary reactions [7, 17-25]. In the past decades, the hydrogen-abstraction/acetyleneaddition (HACA) pathways have been widely used to describe PAH evolution in flame, and are the framework of most PAH reaction mechanisms [7, 20, 26-30]. In the HACA framework, pyrene can be formed starting from phenyl radical via the reaction pathway of phenyl radical + acetylene $\rightarrow$ phenylacetylene $(+$ acetylene $) \rightarrow$ naphthalene (+acetylene) $\rightarrow$ 1(2)-ethynylnaphthalene (+acetylene) $\rightarrow$ phenanthrene (+acetylene) $\rightarrow$ pyrene. Nowadays, these developed PAH sub-mechanisms are widely merged into reaction mechanisms of liquid transportation fuels for PAH and soot predictions in engines [31-38]. However, recent experimental evidence has raised questions regarding the predominance of PAHs constituted of benzene ring structures formed via HACA pathways [39-41]. Johansson et al. [39] investigated PAH growth and soot formation in Ar-diluted $\mathrm{C}_{2} \mathrm{H}_{2} / \mathrm{O}_{2}$ counter-flow diffusion flames using photoionization mass spectrometry method. The results suggested that many PAHs with 5-membered rings may be the main contributors to some observed mass spectra peaks instead of PAHs with strong thermodynamic stability (like phenanthrene and pyrene). Furthermore, chemical structures with 5membered ring were directly observed by Shulz et al. [40] using high-resolution atomic force microscopy in a premixed $\mathrm{C}_{2} \mathrm{H}_{4}$-air flame. However, the only $\mathrm{PAH}$ with a 5-membered ring represented in the current HACA framework is acenaphthylene. The possibility of the formation of other PAHs with 5-membered rings within the HACA framework requires further discussion. With similar methods, Parker et al. [41] carefully examined the reaction of 1- and 2-naphthyl radical and acetylene at $1200 \pm 100 \mathrm{~K}$. They found that the main products were 1and 2-ethynylnaphthalenes, acenaphthylene and diethynylnaphthalenes, neither anthracene nor phenanthrene was detected. Here, we postulate that the site effect of HACA growth pathways may account for the above experimental phenomenon. For example, the formation of new benzene rings is unlikely to happen if the ethynyl 
substitution reactions are more likely to happen at the non-adjacent sites respective to the existing ethynyl chain. This is indirectly supported by recent theoretical studies that show reaction rates of $\mathrm{H}$ abstraction and PAH oxidation are greatly sensitive to the $\mathrm{C}-\mathrm{H}$ site type [42-44].

In this study, we revisit the formation of PAHs within the HACA framework starting from benzene to pyrene, with a special focus on the site effects. The potential energy surface and elementary reaction rate coefficients are obtained using density functional theory (DFT) and transition state theory (TST). Subsequently, the yields of various products are evaluated using a closed homogeneous zero-dimensional batch reactor simulation with boundary conditions extracted from sooting $\mathrm{C}_{2} \mathrm{H}_{4} / \mathrm{O}_{2} / \mathrm{N}_{2}$ flame experiments. Then, correlation discussions are made between theoretical results in this study with PAH experimental results detected using laser induced fluorescence (LIF), vacuum ultraviolet single photon ionization time of flight mass spectrometry (TOFMS), and gas-chromatography-mass spectrometry (GC-MS) techniques.

\section{Calculation details}

The reaction network in this study includes 186 elementary reactions, which can be divided into benzenenaphthalene $\left(A_{1}-A_{2}\right)$, naphthalene-acenaphthylene-phenanthrene $\left(A_{2}-A_{2} R_{5}-A_{3}\right)$ and phenanthrene-pyrene $\left(A_{3}-A_{4}\right)$ reaction systems. The structures of all local minima and transition states (TSs) were optimized at DFT with B3LYP hybrid functional 6-311+G(d,p) basis set [45]. The frequencies were obtained using the same method, then a factor of 0.967 was used for scaling [46]. It should be noted that this scaling factor is originally obtained for B3LYP hybrid functional and 6-311+G(3df,2p) basis set [47]. The sum of electronic and zero-point energies were firstly obtained at DFT B3LYP 6-311+G(d,p) level. To improve the energy accuracy, the CBS-QB3 [48] method was then employed to refine the energy in $A_{1}-A_{2}$ reaction system. The deviations of energy barriers between DFT B3LYP 6-311 +G(d,p) and CBS-QB3 levels in the $\mathrm{A}_{1}-\mathrm{A}_{2}$ reaction system were utilized to correct systematic errors in larger analogous reaction systems. Restricted wave function calculations were employed for close-shell structures, and unrestricted wave function calculations were employed for open-shell structure. Intrinsic reaction coordinate (IRC) calculations [49] were carried out to double-check that the TSs were connected with the corresponding reactant and product. The Gaussian 09 program package was selected for quantum chemistry calculation [50].

The biomolecular $\mathrm{H}$ abstraction and $\mathrm{C}_{2} \mathrm{H}_{2}$ addition reactions are essential to the HACA pathway. Their reaction rate coefficients are almost pressure-independent in the temperature range of 500-1700 $\mathrm{K}$, especially for $\mathrm{H}$ abstraction reactions $[42,51]$. Generally, the $\mathrm{PAH}$ adduct intermediate generated from $\mathrm{H}$ abstraction and $\mathrm{C}_{2} \mathrm{H}_{2}$ addition reaction leads to one product via the sole reaction channel. Few PAH adduct intermediates can split two different reaction channels, but the yield of the minor reaction products is negligible in this case. Therefore, it is 
not necessary to explore the issue of pressure-dependent branching ratios starting from the single molecule $\mathrm{PAH}$ adduct intermediates. In this study, the rate coefficients of all elementary reactions were evaluated at the highpressure limit using transition state theory (TST) [19]. Low frequency internal rotations were regarded as 1-D unsymmetrical hindered rotations. The torsional potential energy and rotation constant as function of dihedral angle were calculated at DFT B3LYP 6-31 G level [28]. Eckart tunneling correction and reaction pathway degeneration were considered [52].

To evaluate the yield of various PAHs produced by the HACA pathway in sooting flames, the concentrations of PAHs were predicted using PAH mechanisms that consider site effects in a premixed $\mathrm{C}_{2} \mathrm{H}_{4} / \mathrm{O}_{2} / \mathrm{N}_{2}$ flame using the premixed burner model in the Chemkin-Pro software. Here, the PAH mechanism consists of the USC II base mechanism and the investigated 186 elementary reactions. The Lennard-Jones transport parameters of new species are calculated using the method recommended by Wang et al. [53]. The thermodynamics parameters of new species are assumed to be equal to that of the corresponding PAH isomer considered in the ABF mechanism [26]. Generally, thermodynamics parameters determine the heat of reaction and reaction equilibrium constant in flame modeling. The former affects the flame temperature, and the latter can be utilized to get the reaction coefficients of reversible reactions. PAH reactions are unlikely to change the flame temperature due to the low concentrations of PAH found in a flame. On the other hand, rate coefficients of all reverse reactions are also calculated using TST method. Therefore, assumptions of thermodynamics parameters are acceptable in this study. The flame conditions including temperature, equivalence ratio, velocity of inlet-gas and pressure are based on experimental conditions in [54]. The mixture-averaged transport formulation is employed to calculate the species ordinary diffusion coefficients and fluxes. The maximum number of grid points allowed in simulation is set to 500. The maximum gradient and curvature allowed between grid points are given as 0.2 and 0.5 , respectively.

\section{Results and discussion}

\subsection{Potential energy surface}

\subsubsection{Benzene-naphthalene reaction system}

The potential energy surface $(\mathrm{PES})$ of benzene $\left(A_{1}\right)$ - naphthalene $\left(A_{2}\right)$ reaction system is shown in Fig.1. The first $\mathrm{H}$ abstraction and $\mathrm{C}_{2} \mathrm{H}_{2}$ addition lead to the unstable intermediate $\mathrm{B}-\mathrm{CS} 13$ (Benzene $+\mathrm{H} \rightarrow \mathrm{B}-\mathrm{CS} 12\left(+\mathrm{C}_{2} \mathrm{H}_{2}\right)$ $\rightarrow$ B-CS13). At flame temperatures, unstable species are likely to evolve into steady species. Once the B-CS13 structure is formed, the $\mathrm{H}$ elimination from the acetylene chain of B-CS13 may happen with the energy barrier of $38.4 \mathrm{kcal} / \mathrm{mol}(\mathrm{B}-\mathrm{CS} 13 \rightarrow \mathrm{B}-\mathrm{CS} 14+\mathrm{H}, 38.4 \mathrm{kcal} / \mathrm{mol})$, and generate phenylacetylene (B-CS14) [18, 55]. It should be noted that B-CS14 is much more stable than B-CS13, although the $\mathrm{H}$ elimination reaction is an endothermic process. The reason why the energy of B-CS14+H is higher than that of B-CS13 in PES is because a radical on $\underline{a}$ hydrogen atom is less stable than a radical on B-CS13.The di-substituted species B-CS8, B-CS10 
and $\mathrm{B}-\mathrm{CS} 11$ can be formed through the second $\mathrm{H}$ abstraction, $\mathrm{C}_{2} \mathrm{H}_{2}$ addition and $\mathrm{H}$ elimination reactions. Specifically, the pathways of CS14 $+\mathrm{H} \rightarrow \mathrm{B}-\mathrm{CS} 1\left(+\mathrm{C}_{2} \mathrm{H}_{2}\right) \rightarrow$ B-CS4 $(-\mathrm{H}) \rightarrow \mathrm{B}-\mathrm{CS} 11+\mathrm{H}, \mathrm{CS} 14+\mathrm{H} \rightarrow \mathrm{B}-\mathrm{CS} 2$ $\left(+\mathrm{C}_{2} \mathrm{H}_{2}\right) \rightarrow \mathrm{B}-\mathrm{CS} 7(-\mathrm{H}) \rightarrow \mathrm{B}-\mathrm{CS} 8+\mathrm{H}$ and CS14 $+\mathrm{H} \rightarrow \mathrm{B}-\mathrm{CS} 3\left(+\mathrm{C}_{2} \mathrm{H}_{2}\right) \rightarrow \mathrm{B}-\mathrm{CS} 9(-\mathrm{H}) \rightarrow \mathrm{B}-\mathrm{CS} 10+\mathrm{H}$ lead to the formation of B-CS11, B-CS8 and B-CS10 respectively. Naphthyl radical can be isomerized from B-CS5, which is the conformer of B-CS4 and forms via the $\mathrm{C}-\mathrm{C}$ rotation reaction (B-CS4 $\rightarrow$ B-CS5, $4.0 \mathrm{kcal} / \mathrm{mol}$ ). Such conformation change is_a low-barrier process, and can reach equilibrium quickly. The energy barrier of the cyclization reaction which generates naphthyl radical is $6.4 \mathrm{kcal} / \mathrm{mol}$ (B-CS5 $\rightarrow$ B-CS6). In terms of energy barriers, the cyclization rotation reaction $(\mathrm{B}-\mathrm{CS} 5 \rightarrow \mathrm{B}-\mathrm{CS} 6,6.4 \mathrm{kcal} / \mathrm{mol})$ is more likely to happen, as its energy barrier is lower than that of $\mathrm{H}$ elimination $(\mathrm{B}-\mathrm{CS} 5 \rightarrow \mathrm{B}-\mathrm{CS} 11+\mathrm{H}, 38.6 \mathrm{kcal} / \mathrm{mol}$ ) by $32.2 \mathrm{kcal} / \mathrm{mol}$.

Alternatively, the intramolecular $\mathrm{H}$ transfer from the benzene ring to the acetylene chain is also a reaction possibility (B-CS13 $\rightarrow$ B-CS15, $26.7 \mathrm{kcal} / \mathrm{mol})$, which generates B-CS15 with an active C site on the benzene ring. The active $\mathrm{C}$ site makes the second $\mathrm{C}_{2} \mathrm{H}_{2}$ addition feasible (B-CS15 $+\mathrm{C}_{2} \mathrm{H}_{2} \rightarrow \mathrm{B}-\mathrm{CS} 16,3.3 \mathrm{kcal} / \mathrm{mol}$ ), and the $\mathrm{A}_{2}$ forms via the subsequent $\mathrm{C}-\mathrm{C}$ rotation $(\mathrm{B}-\mathrm{CS} 16 \rightarrow \mathrm{B}-\mathrm{CS} 17,3.4 \mathrm{kcal} / \mathrm{mol})$, cyclization $(\mathrm{B}-\mathrm{CS} 17 \rightarrow \mathrm{B}-$ $\mathrm{CS} 18,1.8 \mathrm{kcal} / \mathrm{mol}$ ), and $\mathrm{H}$ elimination $\left(\mathrm{B}-\mathrm{CS} 18 \rightarrow \mathrm{A}_{2}+\mathrm{H}, 28.6 \mathrm{kcal} / \mathrm{mol}\right.$ ) reactions. However, the subsequent kinetics result shows that the $\mathrm{A}_{2}$ formation from the pathway of B-CS13 $\rightarrow$ B-CS15 $\rightarrow$ B-CS16 $\rightarrow$ B-CS17 $\rightarrow$ $\mathrm{B}-\mathrm{CS} 18 \rightarrow \mathrm{A}_{2}+\mathrm{H}$ (named as the Frenklach route in this study) can be ignored at flame temperatures, comparing with the pathway of B-CS13 $\rightarrow$ B-CS14 $\rightarrow$ B-CS1 $\rightarrow$ B-CS4 $\rightarrow$ B-CS5 $\rightarrow$ B-CS6 $\rightarrow$ A2. Here, the BittnerHoward route [56] where the second $\mathrm{C}_{2} \mathrm{H}_{2}$ attacks the acetylene chain of B-CS13 is not considered in this study, because the reaction probability is greatly limited by the instability of B-CS13 at flame temperature as discussed by Mebel et al. [51].

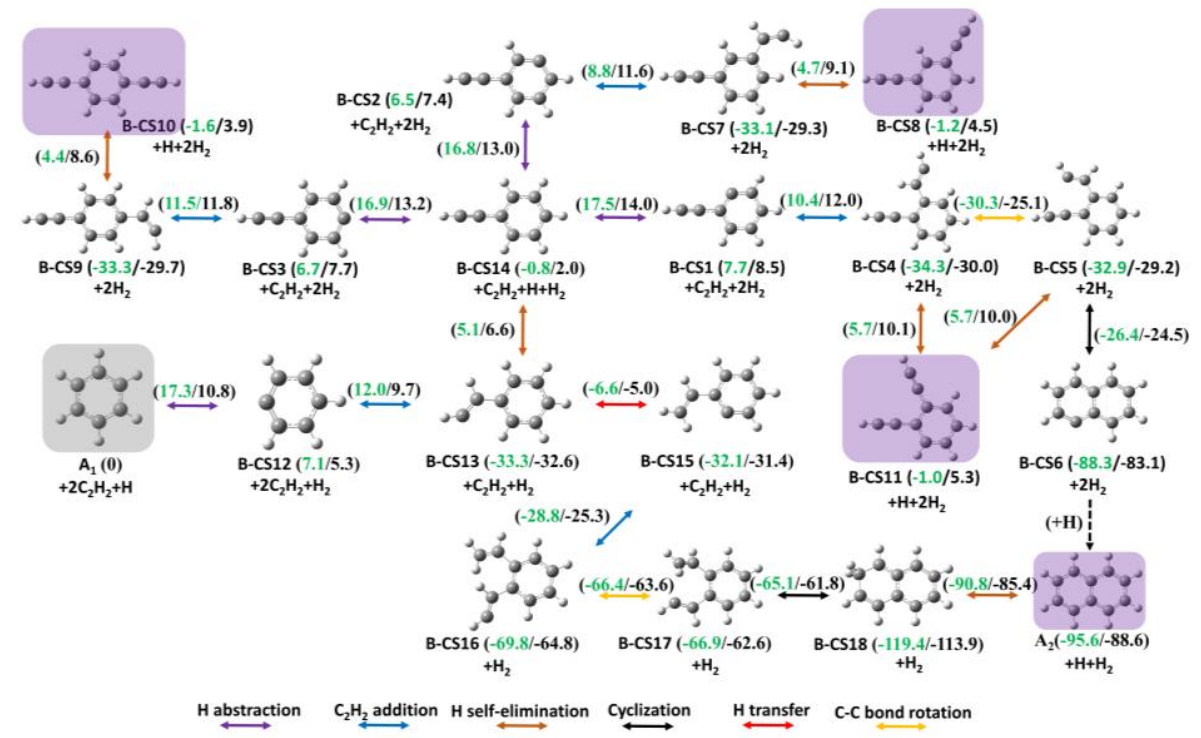

Fig.1. The potential energy surface of $\mathrm{A}_{1}-\mathrm{A}_{2}$ reaction system, energies are calculated at CBS-QB3 (labeled as green) and DFT B3LYP 6-311+g(d,p) (labeled as black) respectively. 
Accurate energy barriers are necessary to obtain reliable reaction rate coefficients. However, the demand of computational resource increases rapidly with the molecule size in energy calculation using high-level methods. In this study, the energy barriers in $\mathrm{A}_{1}-\mathrm{A}_{2}$ reaction system are calculated at CBS-QB3 and DFT B3LYP 6$311+\mathrm{G}(\mathrm{d}, \mathrm{p})$ levels. The root-mean-square deviation of CBS-QB3 energy is $1.49 \mathrm{kcal} / \mathrm{mol}$ [48]. Based on the comparison results of energy barriers in $\mathrm{A}_{1}-\mathrm{A}_{2}$ reaction system, energy barrier corrections are introduced for the larger analogous reaction. As shown in Fig.1, the PAHs growth reactions within HACA frame can be classified into six types: 1) $\mathrm{H}$ abstraction, 2) $\mathrm{C}_{2} \mathrm{H}_{2}$ addition, 3) $\mathrm{H}$ transfer, 4) $\mathrm{H}$ elimination, 5) Cyclization, 6) C-C bond rotation. The energy barrier calculated at DFT level is reliable except for the $\mathrm{H}$ abstraction reaction type (PAH + $\mathrm{H} \rightarrow$ PAH radical $+\mathrm{H}_{2}$ ). As shown in Table 1, the deviations of energy barriers are within 0.1-2.2 kcal $/ \mathrm{mol}$ for $\mathrm{C}_{2} \mathrm{H}_{2}$ addition, $\mathrm{H}$ transfer, $\mathrm{H}$ elimination, cyclization and $\mathrm{C}-\mathrm{C}$ bond rotation reactions, but the value increases to 6.3-6.6 kcal/mol for $\mathrm{H}$ abstraction reactions and 4.3-4.7 kcal/mol for the reverse reactions (PAH radical $+\mathrm{H}_{2} \rightarrow$ $\mathrm{PAH}+\mathrm{H}$ ). Therefore, the energy corrections of 6.5 and $4.7 \mathrm{kcal} / \mathrm{mol}$ are taken for the $\mathrm{H}$ abstraction and $\mathrm{H}_{2}$ addition reactions in the kinetic calculations, and the DFT B3LYP 6-311+G(d,p) energy is used for the rest of reactions. The similar treatment can be seen in ref [42, 57]. The reported energy barrier calculated at G3(MP2,CC) method is also taken for comparison. As shown in Table 1, the results obtained from CBS-QB3 method is highly close to that from G3(MP2,CC), indicating that the energy correction treatment from CBS-QB3 to DFT B3LYP $6-311+\mathrm{G}(\mathrm{d}, \mathrm{p})$ is reasonable.

Table1. Comparisons of the energy barriers (kcal/mol) obtained at CBS-QB3, G3(MP2,CC), and DFT methods.

\begin{tabular}{|c|c|c|c|c|c|}
\hline$\overline{\text { Reaction }}$ & CBS-QB3 & DFT & Difference & G3(MP2,CC) & Reaction type \\
\hline Benzene $+\mathrm{H} \rightarrow \mathrm{B}-\mathrm{CS} 12+\mathrm{H}_{2}$ & 17.3 & 10.8 & 6.5 & $17.0[42]$ & \\
\hline $\mathrm{B}-\mathrm{CS} 14+\mathrm{H} \rightarrow \mathrm{B}-\mathrm{CS} 1+\mathrm{H}_{2}$ & 18.3 & 12.0 & 6.3 & & \\
\hline $\mathrm{B}-\mathrm{CS} 14+\mathrm{H} \rightarrow \mathrm{B}-\mathrm{CS} 2+\mathrm{H}_{2}$ & 17.6 & 11.0 & 6.6 & & $\mathrm{H}$ abstraction \\
\hline $\mathrm{B}-\mathrm{CS} 14+\mathrm{H} \rightarrow \mathrm{B}-\mathrm{CS} 3+\mathrm{H}_{2}$ & 17.7 & 11.2 & 6.5 & & \\
\hline B-CS12 $+\mathrm{H}_{2} \rightarrow$ Benzene $+\mathrm{H}$ & 10.2 & 5.5 & 4.7 & & \\
\hline $\mathrm{B}-\mathrm{CS} 1+\mathrm{H}_{2} \rightarrow \mathrm{B}-\mathrm{CS} 14+\mathrm{H}$ & 9.8 & 5.5 & 4.3 & & \\
\hline $\mathrm{B}-\mathrm{CS} 2+\mathrm{H}_{2} \rightarrow \mathrm{B}-\mathrm{CS} 14+\mathrm{H}$ & 10.3 & 5.6 & 4.7 & $10.3^{\mathrm{a}}[58]$ & $\mathrm{H}_{2}$ addition \\
\hline $\mathrm{B}-\mathrm{CS} 3+\mathrm{H}_{2} \rightarrow \mathrm{B}-\mathrm{CS} 14+\mathrm{H}$ & 10.2 & 5.5 & 4.7 & & \\
\hline $\mathrm{B}-\mathrm{CS} 1+\mathrm{C}_{2} \mathrm{H}_{2} \rightarrow \mathrm{B}-\mathrm{CS} 4$ & 2.7 & 3.5 & 0.8 & $3.1[51]$ & \\
\hline $\mathrm{B}-\mathrm{CS} 2+\mathrm{C}_{2} \mathrm{H}_{2} \rightarrow \mathrm{B}-\mathrm{CS} 7$ & 2.3 & 4.2 & 1.9 & & $\mathrm{C}_{2} \mathrm{H}_{2}$ addition \\
\hline $\mathrm{B}-\mathrm{CS} 3+\mathrm{C}_{2} \mathrm{H}_{2} \rightarrow \mathrm{B}-\mathrm{CS} 9$ & 4.8 & 4.1 & 0.7 & & \\
\hline $\mathrm{B}-\mathrm{CS} 12+\mathrm{C}_{2} \mathrm{H}_{2} \rightarrow \mathrm{B}-\mathrm{CS} 13$ & 4.9 & 4.4 & 0.5 & $3.6[51]$ & \\
\hline $\mathrm{B}-\mathrm{CS} 13 \rightarrow \mathrm{B}-\mathrm{CS} 15$ & 26.7 & 27.6 & 0.9 & $27.6[51]$ & $\mathrm{H}$ transfer \\
\hline B-CS7 $\rightarrow$ B-CS $8+H$ & 37.8 & 38.4 & 0.6 & & \\
\hline $\mathrm{B}-\mathrm{CS} 9 \rightarrow \mathrm{B}-\mathrm{CS} 10+\mathrm{H}$ & 37.7 & 38.3 & 0.6 & & H elimination \\
\hline $\mathrm{B}-\mathrm{CS} 4 \rightarrow \mathrm{B}-\mathrm{CS} 11+\mathrm{H}$ & 40.0 & 40.1 & 0.1 & $38.8[51]$ & \\
\hline $\mathrm{B}-\mathrm{CS} 18 \rightarrow \mathrm{A} 2+\mathrm{H}$ & 28.6 & 28.5 & 0.1 & $27.8[51]$ & \\
\hline $\mathrm{B}-\mathrm{CS} 5 \rightarrow \mathrm{B}-\mathrm{CS} 6$ & 6.5 & 4.7 & 1.8 & & Cyclization \\
\hline
\end{tabular}




\begin{tabular}{llllll}
$-\mathrm{CS} 17 \rightarrow \mathrm{B}-\mathrm{CS} 18$ & 1.8 & 0.8 & 1.0 & & \\
\hline $\mathrm{B}-\mathrm{CS} 4 \rightarrow \mathrm{B}-\mathrm{CS} 5$ & 4.0 & 4.9 & 0.9 & & C-C bond rotation \\
$\mathrm{B}-\mathrm{CS} 16 \rightarrow \mathrm{B}-\mathrm{CS} 17$ & 3.4 & 1.2 & 2.2 & $2.8[51]$ & \\
\hline
\end{tabular}

athe energy barrier for 2-naphthyl radical $+\mathrm{H}_{2} \rightarrow$ naphthalene $+\mathrm{H}$ reaction at G3(MP2,CC) level [58].

\subsubsection{Naphthalene-acenaphthylene-phenanthrene reaction system}

Naphthalene is the simplest PAHs with zig-zag surface, which can lead to the formation of acenaphthylene and 1-naphthyl radical (N1-CS1) if the $\mathrm{H}$ atom near the zig-zag surface of $\mathrm{A}_{2}$ is abstracted by the surrounding $\mathrm{H}$ atom $\left(\mathrm{A}_{2}+\mathrm{H} \rightarrow \mathrm{N} 1-\mathrm{CS} 1+\mathrm{H}_{2}, \quad 11.2 \mathrm{kcal} / \mathrm{mol}\right)$, as shown in Fig.2. Acenaphthylene (N1-CS4, $\left.\mathrm{A}_{2} \mathrm{R}_{5}\right)$ and 1ethynylnaphthalene (N1-CS5) form via the pathways of $\mathrm{N} 1-\mathrm{CS} 1+\mathrm{C}_{2} \mathrm{H}_{2} \rightarrow \mathrm{N} 1-\mathrm{CS} 2 \rightarrow \mathrm{N} 1-\mathrm{CS} 3 \rightarrow \mathrm{N} 1-\mathrm{CS} 4+\mathrm{H}$ and $\mathrm{N} 1-\mathrm{CS} 1+\mathrm{C}_{2} \mathrm{H}_{2} \rightarrow \mathrm{N} 1-\mathrm{CS} 2 \rightarrow \mathrm{N} 1-\mathrm{CS} 5+\mathrm{H}$. In this reaction network, phenanthrene $\left(\mathrm{A}_{3}\right)$ can be given by the Frenklach route shown as $\mathrm{N} 1-\mathrm{CS} 2 \rightarrow \mathrm{N} 1-\mathrm{CS} 33 \rightarrow \mathrm{N} 1-\mathrm{CS} 34 \rightarrow \mathrm{N} 1-\mathrm{CS} 35 \rightarrow \mathrm{N} 1-\mathrm{CS} 35 \rightarrow \mathrm{N} 1-\mathrm{CS} 37 \rightarrow \mathrm{A}_{3}+\mathrm{H}$ in $\mathrm{Fig} .2$, where the energy barrier of each reaction step is close to that of B-CS13 $\rightarrow \mathrm{B}-\mathrm{CS} 15 \rightarrow \mathrm{B}-\mathrm{CS} 16 \rightarrow \mathrm{B}-\mathrm{CS} 17 \rightarrow \mathrm{B}-$ $\mathrm{CS} 18 \rightarrow \mathrm{A}_{2}+\mathrm{H}$. The formation of 2-ethynylnaphthalene (N2-CS3) and $\mathrm{A}_{3}$ is feasible if the $\mathrm{H}$ atom near the freeedge surface of $A_{2}$ is abstracted, and the features of the formation pathways are almost the same with those of $\mathrm{N} 1-\mathrm{CS} 5$ and $\mathrm{A}_{3}$ starting from N1-CS2. If the N2-CS38 proceeds with cyclization reaction (N1-CS38 $\rightarrow$ N1-CS39, $12.5 \mathrm{kcal} / \mathrm{mol}$ ), we would observe the formation of N2-CS39 with 5-membered ring, which can evolve to the plane structure N2-CS40 via the H elimination reaction (N2-CS39 $\rightarrow$ N2-CS40+H). The N2-CS40 species may be the main product in this network in terms of energy barrier, as the energy barriers of $\mathrm{A}_{2}+\mathrm{H} \rightarrow \mathrm{N} 2-\mathrm{CS} 1+\mathrm{H}_{2}, \mathrm{~N} 2-$ $\mathrm{CS} 2 \rightarrow \mathrm{N} 2-\mathrm{CS} 37$ and N2-CS38 $\rightarrow \mathrm{N} 2-\mathrm{CS} 39$ are lower than the corresponding branch reaction $\mathrm{A}_{2}+\mathrm{H} \rightarrow \mathrm{N} 1-\mathrm{CS} 1+\mathrm{H}_{2}$, $\mathrm{N} 2-\mathrm{CS} 2 \rightarrow \mathrm{N} 2-\mathrm{CS} 3+\mathrm{H}$ and N2-CS38 $\rightarrow \mathrm{N} 2-\mathrm{CS} 41$ by $0.3,11.3$ and $10.8 \mathrm{kcal} / \mathrm{mol}$. 


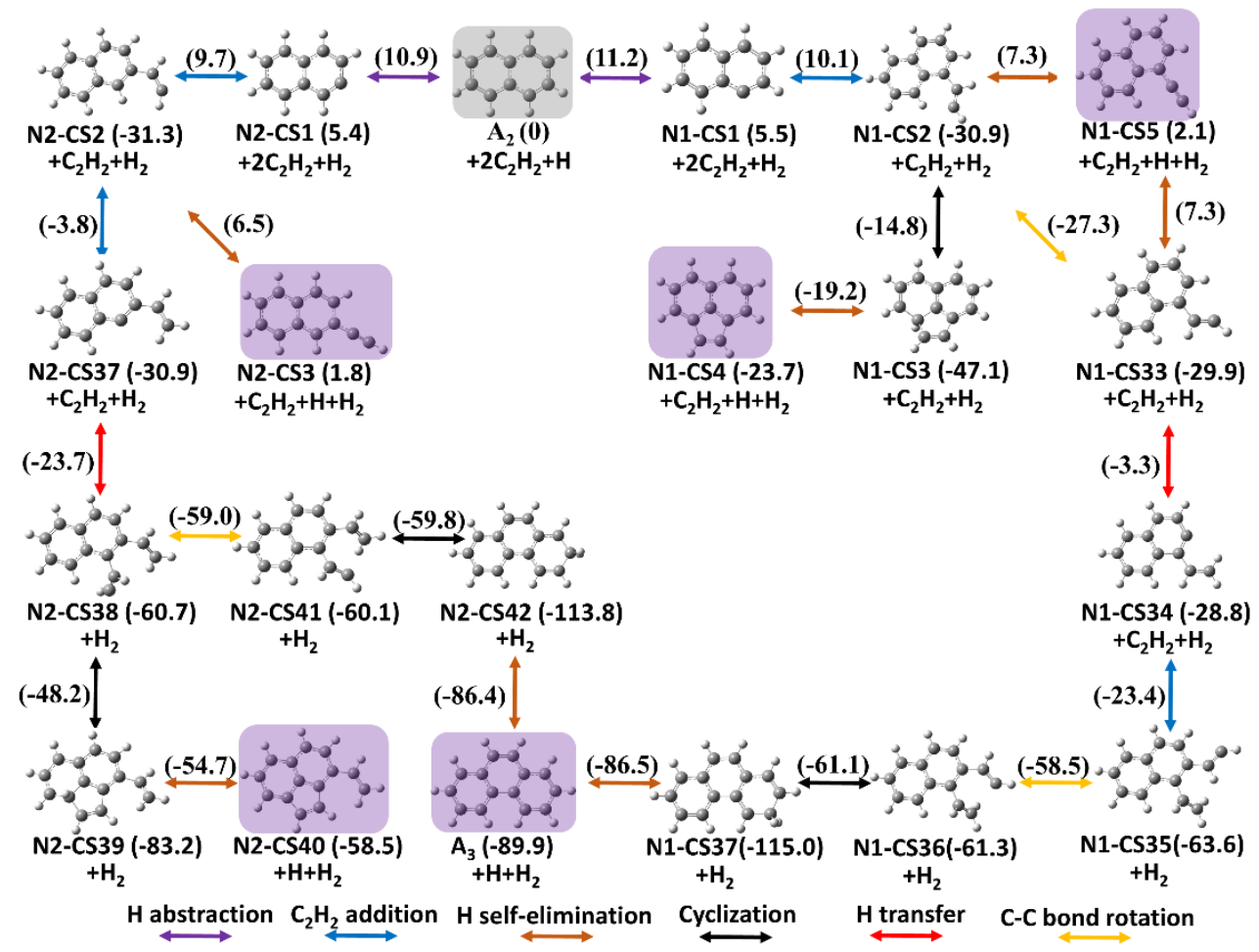

Fig.2. The potential energy surface of $\mathrm{A}_{2}-\mathrm{A}_{2} \mathrm{R}_{5}-\mathrm{A}_{3}$ reaction system, energies are calculated at DFT B3LYP 6-311+g(d,p) level.

To perfect the $\mathrm{A}_{3}$ formation network, the further evolutions of 1-ethynylnaphthalene and 2-ethynylnaphthalene were investigated. The main formation pathway of $\mathrm{A}_{3}$ radical in current PAH mechanisms consists of the $\mathrm{H}$ abstraction reaction $\left(\mathrm{N} 1-\mathrm{CS} 5+\mathrm{H} \rightarrow \mathrm{N} 1-\mathrm{CS} 6+\mathrm{H}_{2}\right.$ or $\mathrm{N} 2-\mathrm{CS} 3+\mathrm{H} \rightarrow \mathrm{N} 2-\mathrm{CS} 10+\mathrm{H}_{2}$ ), and $\mathrm{C}_{2} \mathrm{H}_{2}$ addition to the adjacent $\mathrm{C}$ atom relative to the side chain of 1-ethynylnaphthalene and 2-ethynylnaphthalene $\left(\mathrm{N} 1-\mathrm{CS} 6+\mathrm{C}_{2} \mathrm{H}_{2} \rightarrow \mathrm{N} 1-\mathrm{CS} 13\right.$ or $\left.\mathrm{N} 2-\mathrm{CS} 10+\mathrm{C}_{2} \mathrm{H}_{2} \rightarrow \mathrm{N} 2-\mathrm{CS} 17\right), \mathrm{C}-\mathrm{C}$ rotation $(\mathrm{N} 1-\mathrm{CS} 13 \rightarrow \mathrm{N} 1-\mathrm{CS} 27$ or $\mathrm{N} 2-\mathrm{CS} 17 \rightarrow \mathrm{N} 2-\mathrm{CS} 43$ ) and cyclization reactions $(\mathrm{N} 1-\mathrm{CS} 27 \rightarrow \mathrm{N} 1-\mathrm{CS} 20$ or $\mathrm{N} 2-\mathrm{CS} 43 \rightarrow \mathrm{N} 2-\mathrm{CS} 44)$, as shown in Fig 3-4. In this study, all possible $\mathrm{H}$ abstraction reactions on 1-ethynylnaphthalene (N1-CS5) and 2-ethynylnaphthalene (N2-CS3) are explored. It was found that the energy barrier of $\mathrm{H}$ abstraction was sensitive to the existing acetylene chain. The energy barrier of $\mathrm{H}$ abstraction beside the acetylene chain of $\mathrm{N} 1-\mathrm{CS} 5\left(\mathrm{~N} 1-\mathrm{CS} 5+\mathrm{H} \rightarrow \mathrm{N} 1-\mathrm{CS} 6+\mathrm{H}_{2}\right.$ and $\left.\mathrm{N} 1-\mathrm{CS} 5+\mathrm{H} \rightarrow \mathrm{N} 1-\mathrm{CS} 12+\mathrm{H}_{2}\right)$ and $\mathrm{N} 2-\mathrm{CS} 3\left(\mathrm{~N} 2-\mathrm{CS} 3+\mathrm{H} \rightarrow \mathrm{N} 1-\mathrm{CS} 4+\mathrm{H}_{2}\right.$ and N2-CS3 $\left.+\mathrm{H} \rightarrow \mathrm{N} 2-\mathrm{CS} 10+\mathrm{H}_{2}\right)$ are slightly higher than that of other site options. This means that the competitiveness of $\mathrm{A}_{3}$ radical (N1-CS20 and N2-CS44) formation starting from N1CS6 and N2-CS10 may be weaker than other channels. Within the HACA growth mode, di-substituted species including N1-CS22, N1-CS23, N1-CS26, N2-CS18, N2-CS19, N2-CS20, N2-CS21, N2-CS22, N2-CS23 and N2CS24 and 5-membered ring species including N2-CS30 and N2-CS35 can be formed. We noted that the thermodynamic stability of the latter is stronger, and the highest energy barrier in its formation pathway is lower than that of the former. This means that the formation of 5-membered ring species is more favorable in this 
reaction networks, which is confirmed by the following kinetic analysis. For brevity, the detail of their formation pathway is not discussed.

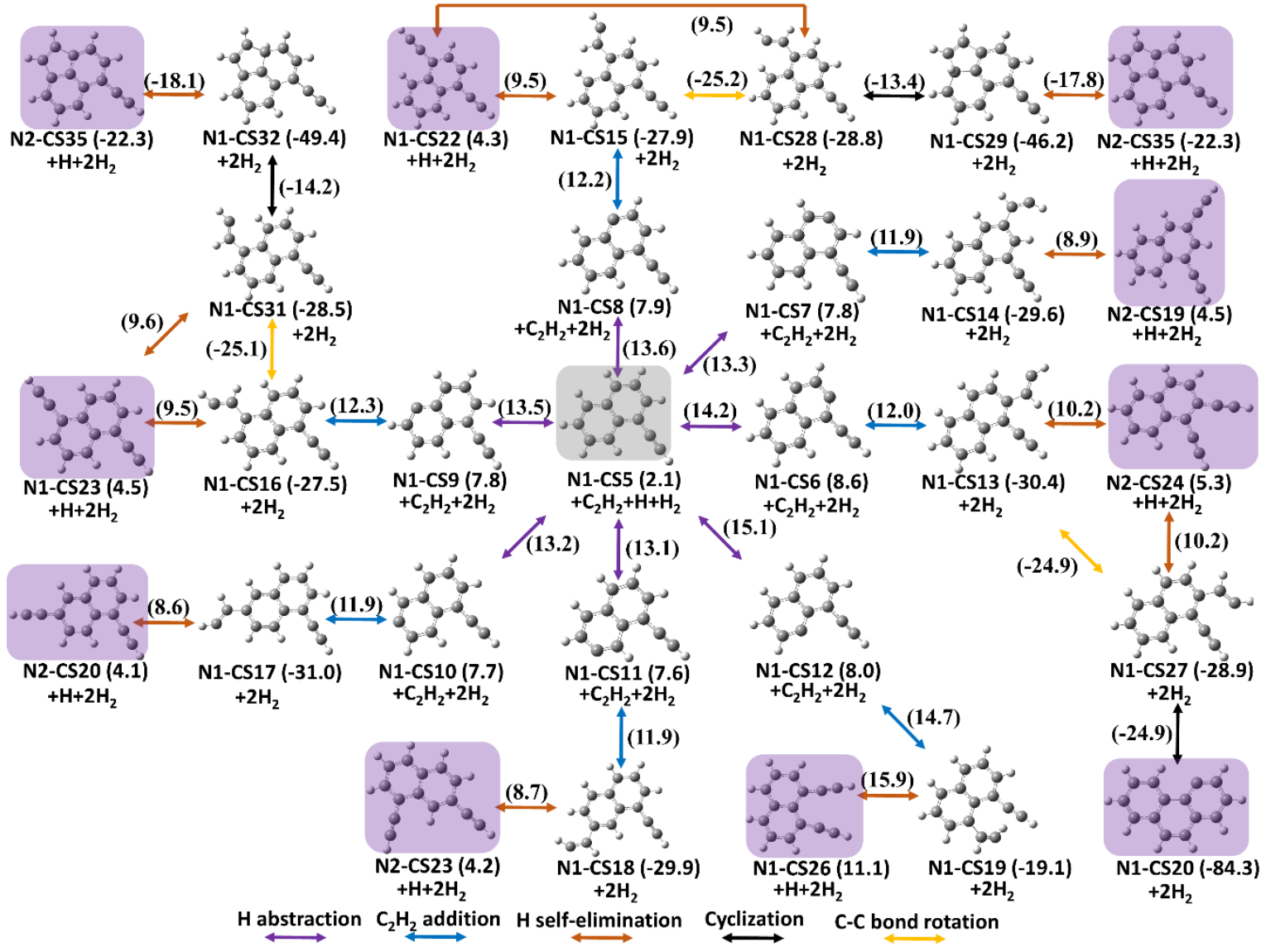

Fig.3. The potential energy surface of N1-CS5-A 3 reaction system, energies are calculated at DFT B3LYP 6-311+g(d,p) level. 


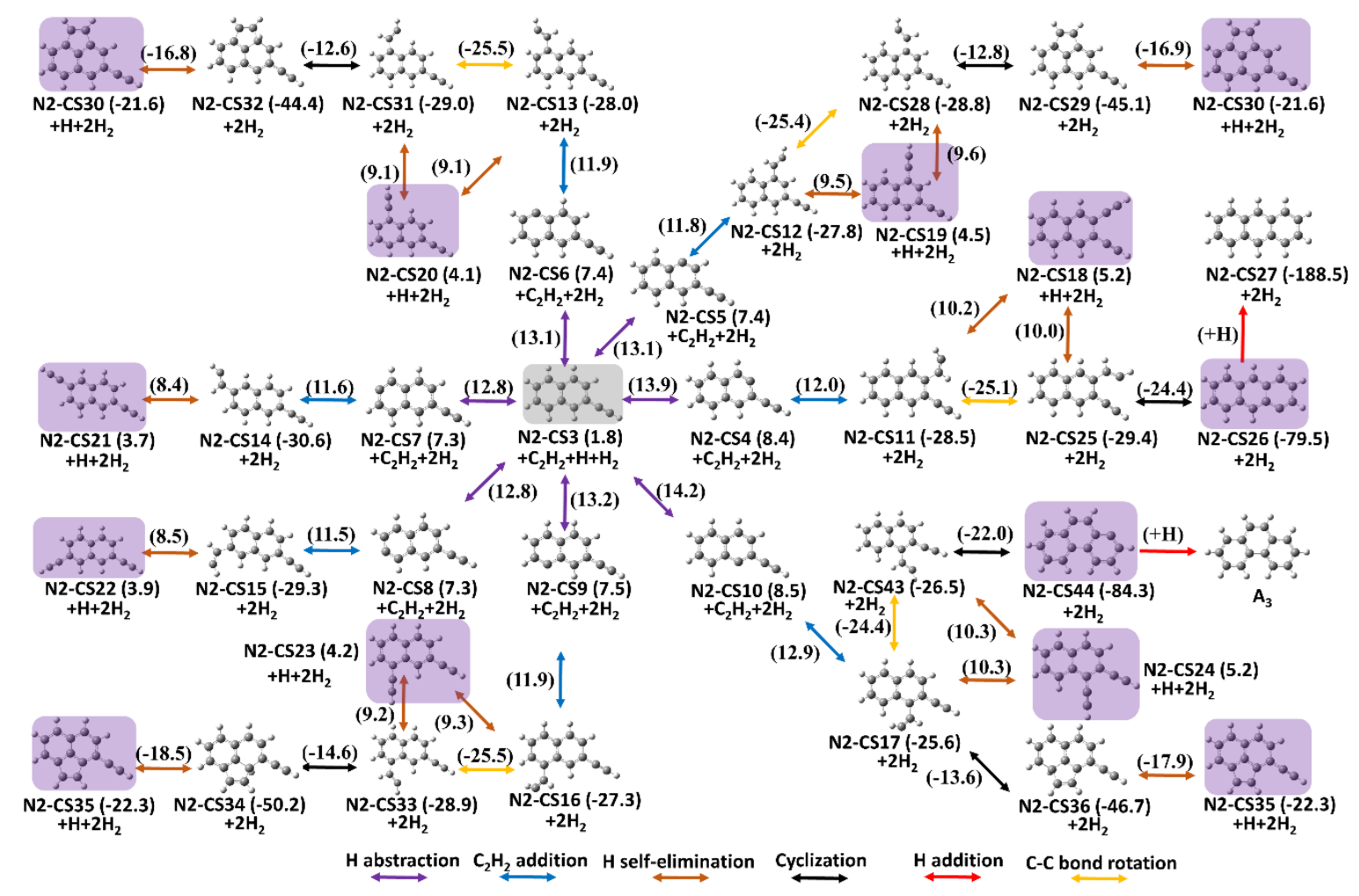

Fig.4. The potential energy surface of N2-CS3-A reaction system, energies are calculated at DFT B3LYP 6-311+g(d,p) level.

\subsubsection{Phenanthrene-pyrene reaction system}

The formation efficiency of new benzene rings in the HACA-based growth process peaks when the reaction happens on the armchair surface site, which make the cyclization reaction easier. In current PAH mechanisms, only $\mathrm{H}$ atoms located on armchair surface sites are allowed to be abstracted, producing the 1-phenanthrene radical and 4-phenanphrene radical (P1-CS1). The conversion rate between 1-phenanthrene radical and 4-phenanthrene radical reaches $3.4 \times 10^{11} \mathrm{~cm}^{3} \mathrm{~mol}^{-1} \mathrm{~s}^{-1}$ at the presence of $\mathrm{H}$ atom at $1500 \mathrm{~K}$. This treatment leads to that pyrene is the dominate product in phenanthrene reaction systems. However, it was found that the $\mathrm{H}$ abstraction and $\mathrm{C}_{2} \mathrm{H}_{2}$ addition were more likely to happen on other $\mathrm{C}$ atoms. As shown in Fig.5, the energy barrier of $\mathrm{H}$ abstraction reaction of $\mathrm{A}_{3}+\mathrm{H} \rightarrow \mathrm{P} 1-\mathrm{CS} 1+\mathrm{H}_{2}(11.5 \mathrm{kcal} / \mathrm{mol})$ and $\mathrm{C}_{2} \mathrm{H}_{2}$ addition reaction of $\mathrm{P} 1-\mathrm{CS} 1+\mathrm{C}_{2} \mathrm{H}_{2} \rightarrow \mathrm{P} 1-\mathrm{CS} 2(7.3$ $\mathrm{kcal} / \mathrm{mol})$ is higher than other similar reactions by at least $0.3\left(\mathrm{~A}_{3}+\mathrm{H} \rightarrow \mathrm{P}(2-5)-\mathrm{CS} 1+\mathrm{H}_{2}\right)$ and $2.7(\mathrm{P}(2-5)-$ $\left.\mathrm{CS} 1+\mathrm{C}_{2} \mathrm{H}_{2} \rightarrow \mathrm{P}(2-5)-\mathrm{CS} 2\right) \mathrm{kcal} / \mathrm{mol}$. This means that $\mathrm{A}_{4}$ may not be one of the main products in this reaction network, which is proved by the following kinetic analysis. Similar to the above reaction networks, the species with 5-membered ring structure P5-CS6 can be formed via the pathways of $\mathrm{A}_{3}+\mathrm{H} \rightarrow \mathrm{P} 4-\mathrm{CS} 1 \rightarrow \mathrm{P} 4-\mathrm{CS} 2 \rightarrow \mathrm{P} 4-$ $\mathrm{CS} 4 \rightarrow \mathrm{P} 4-\mathrm{CS} 5 \rightarrow \mathrm{P} 5-\mathrm{CS} 6$ and $\mathrm{A}_{3}+\mathrm{H} \rightarrow \mathrm{P} 5-\mathrm{CS} 1 \rightarrow \mathrm{P} 5-\mathrm{CS} 2 \rightarrow \mathrm{P} 5-\mathrm{CS} 4 \rightarrow \mathrm{P} 5-\mathrm{CS} 5 \rightarrow \mathrm{P} 5-\mathrm{CS} 6$ if the $\mathrm{C}_{2} \mathrm{H}_{2}$ is attached to 
the zig-zag surface site. The PAHs substituted with $\mathrm{C}_{2} \mathrm{H}$ chain including P1-CS3, P2-CS3, P3-CS3, P4-CS3, P5CS3 will form if the $\mathrm{H}$ elimination reaction happens immediately after the $\mathrm{C}_{2} \mathrm{H}_{2}$ addition reaction.

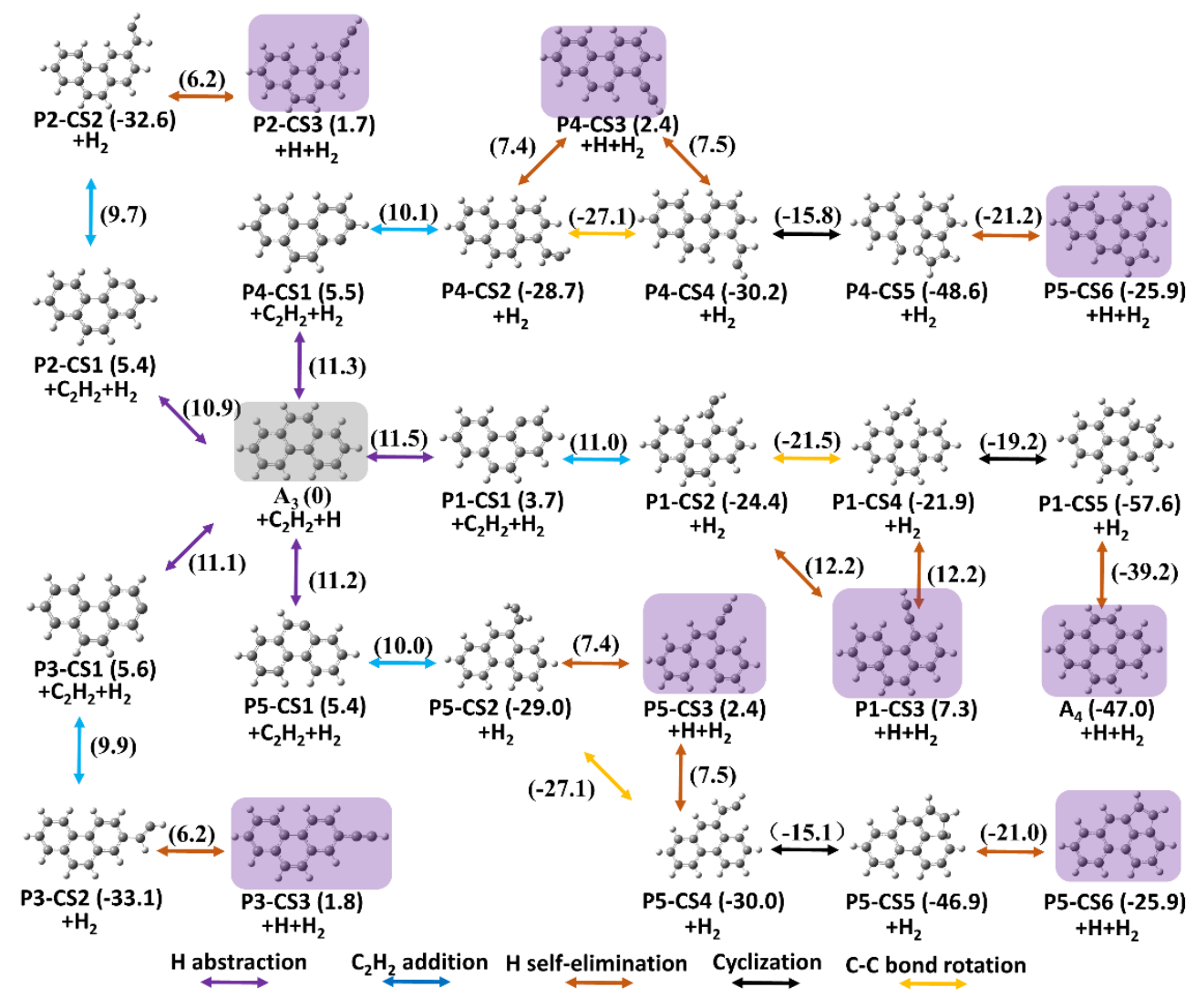

Fig.5. The potential energy surface of $\mathrm{A}_{3}-\mathrm{A}_{4}$ reaction system, energies are calculated at DFT B3LYP 6$311+\mathrm{g}(\mathrm{d}, \mathrm{p})$ level.

\subsection{Kinetical analysis}

The rate coefficients of all elementary reactions are calculated in the temperature range of 500-2500 K using TST method, and the kinetic parameters are listed in Table 2. To examine the theoretical rate coefficients, our rate coefficients for $A_{1}+H$ reaction are compared with the experimental data measured in shock-tubes by Giri et al. [59] and theoretical results evaluated at G3(MP2,CC) level by Semenikhin et al. [42]. A good agreement is obtained, and the deviation is within 1.5 times as shown in Fig. 6 (a). The deviation is likely due to slight differences in energy barriers calculated at CBS-QB3 and G3(MP2,CC) level. The comparison of our rate coefficients for $\mathrm{A}_{1^{-}}+\mathrm{C}_{2} \mathrm{H}_{2}$ with shock-tube experimental data by Heckmann et al. [60] and theoretical data by Mebel et al. [51] further confirm that the calculated rate coefficients in this study are reliable, as shown in Fig.6 (c). Here, our high-pressure rate values are closer to the experimental data in the temperature range of 1000-1500 $\mathrm{K}$, where the rate coefficients of biomolecule $\mathrm{A}_{1^{-}}+\mathrm{C}_{2} \mathrm{H}_{2}$ reaction are expected to be pressure-independent. The deviation of the rate coefficient from theoretical value by Mebel et al [51] at $500 \mathrm{~K}$ is 5.1 times, mainly resulting 
from the differences in energy barriers for $\mathrm{A}_{1}-+\mathrm{C}_{2} \mathrm{H}_{2}$ reaction. The energy barrier is evaluated as $3.6 \mathrm{kcal} / \mathrm{mol}$ at G3(MP2,CC) level in ref. [51] and $4.9 \mathrm{kcal}$ at CBS-QB3 level in the study. A $1.3 \mathrm{kcal} / \mathrm{mol}$ deviation is within the error bars for our calculated energy barrier [48].

In addition, comparisons for $\mathrm{H}$ abstraction reaction and $\mathrm{C}_{2} \mathrm{H}_{2}$ addition reactions were also performed to estimate the accuracy of energy barrier in PAHs reaction systems. The calculated energy barriers of reaction naphthalene $+\mathrm{H} \rightarrow$ 2-naphthyl radical $+\mathrm{H}_{2}$ at G3(MP2,CC) level is $18.6 \mathrm{kcal} / \mathrm{mol}$ in forward direction and $10.3 \mathrm{kcal} / \mathrm{mol}$ in reverse direction [58]. With the energy correction, the corresponding energy barriers for forward and reverse reactions are $17.4 \mathrm{kcal} / \mathrm{mol}(10.9 \mathrm{kcal} / \mathrm{mol}$ with $6.5 \mathrm{kcal} / \mathrm{mol}$ correction) and $10.2 \mathrm{kcal} / \mathrm{mol}(5.5 \mathrm{kcal} / \mathrm{mol}$ with 4.7 $\mathrm{kcal} / \mathrm{mol}$ correction), respectively. Therefore, our energy correction is reliable for the studied $\mathrm{H}$ abstraction reactions. For the addition reaction of $\mathrm{C}_{2} \mathrm{H}_{2}$ and $\mathrm{PAH}$ radical, the energy barrier calculated at DFT B3LYP 6$311+\mathrm{G}(\mathrm{d}, \mathrm{p})$ level is used in this study. The energy barrier calculated at DFT B3LYP 6-311+G(d,p) level is slightly higher than that obtained from G3(MP2,CC) level. For example, the energy barrier for the addition reaction of 2naphthyl radical and $\mathrm{C}_{2} \mathrm{H}_{2}$ is $4.3 \mathrm{kcal} / \mathrm{mol}$ at DFT B3LYP 6-311+G(d,p) level, and the value is $2.6 \mathrm{kcal} / \mathrm{mol}$ at G3(MP2,CC) level [58]. The corresponding rate constant reported here is lower than that provided by Kislov et al [58] by a factor of 1.6 at $1500 \mathrm{~K}$. The difference of energy barriers is still within the uncertainty of G3 based method (1-2 kcal/mol) [61, 62]. Better agreement is observed between the G3(MP2,CC) and DFT B3LYP 6$311+\mathrm{G}(\mathrm{d}, \mathrm{p})$ methods, in terms of the relative energy difference between two $\mathrm{C}_{2} \mathrm{H}_{2}$ addition reactions occurring at different position. The difference of energy barrier for the $\mathrm{C}_{2} \mathrm{H}_{2}$ addition on the armchair site and zig-zag site is 2.7-3 kcal/mol as shown in Fig.5, and is 2.4-3.3 kcal/mol as discussed by Frenklach et al [63] at G3(MP2,CC) level. The yield of products is mainly determined by the branching ratio of competing reactions, which highly relies on the difference of energy barriers between competing reactions. This adds more confidence to the following kinetic analysis, especially the yield analysis.

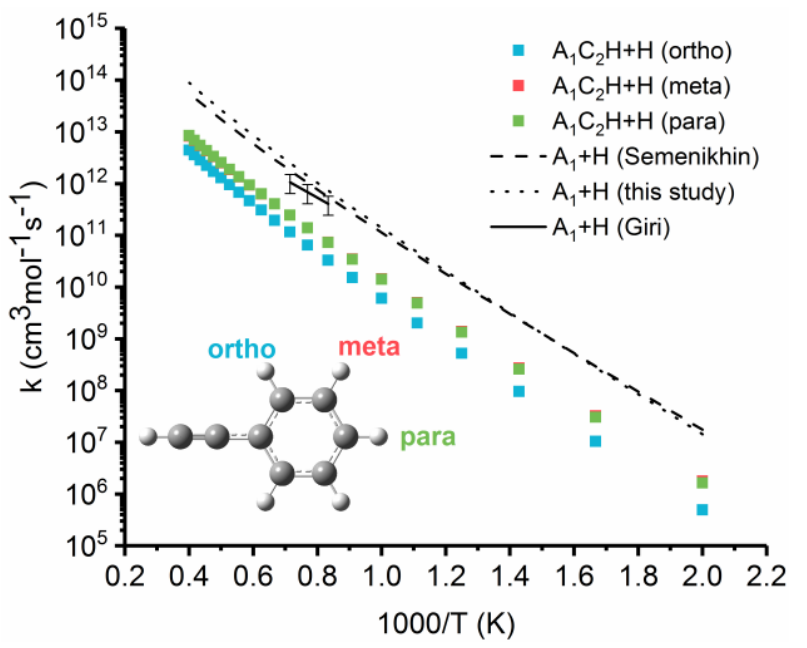

(a)

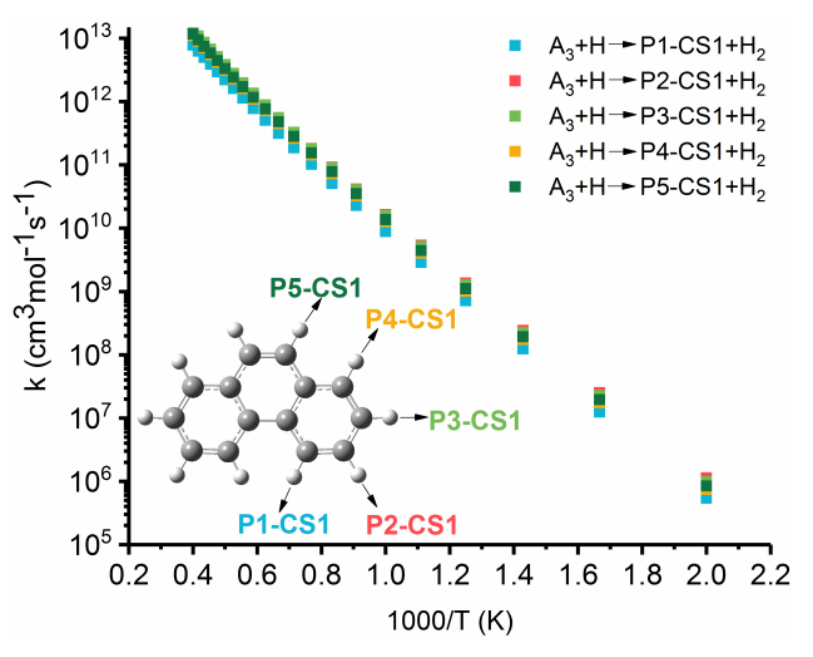

(b) 


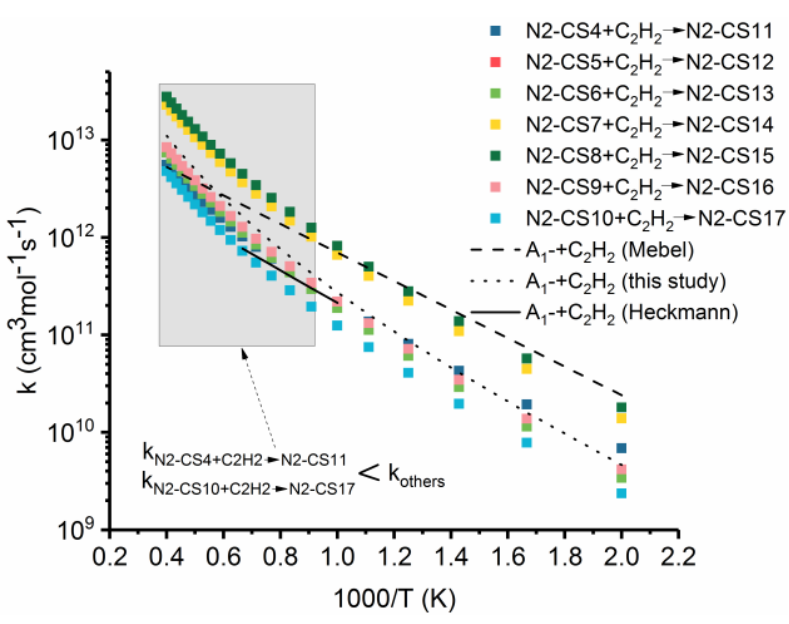

(c)

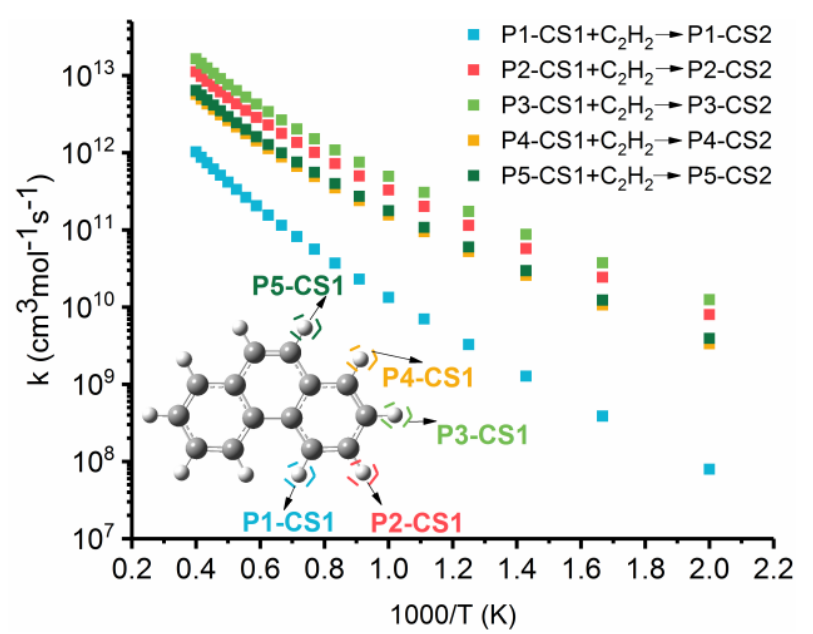

(d)

Fig.6. Rate coefficients for $\mathrm{H}$ abstraction on different positions (a) and different surface sites (b), $\mathrm{C}_{2} \mathrm{H}_{2}$ addition on different positions (c) and different surface sites (d).

As discussed in PES analysis, the various isomer products can be formed by considering site effects in the HACA framework. Among all elementary reaction types, the $\mathrm{H}$ abstraction from the close-shell $\mathrm{PAH}$ molecules and $\mathrm{C}_{2} \mathrm{H}_{2}$ addition to PAH radicals determine the yield of products. Here, the sensitivity of rate coefficients for $\mathrm{H}$ abstraction and $\mathrm{C}_{2} \mathrm{H}_{2}$ addition to the site position relative to the $\mathrm{C}_{2} \mathrm{H}$ chain (ortho-, meta- and para-position) and surface site type (zig-zag, free-edge and armchair) is shown in Fig.6 (a)-(d). Fig.6 (a) shows that the environmental free H atom is inclined to attack the $\mathrm{H}$ atom on the carbon at the meta- and para-position relative to the $\mathrm{C}_{2} \mathrm{H}$ chain on $\mathrm{A}_{1} \mathrm{C}_{2} \mathrm{H}$ molecule. The rate coefficient of $\mathrm{H}$ abstraction reaction on ortho-position is lower than that on meta- and para-position by a factor of 2.08 at $1500 \mathrm{~K}$. According to the Arrhenius equation, the difference of rate coefficient can be introduced by the energy barrier and collision frequency. The energy barrier of $\mathrm{A}_{1} \mathrm{C}_{2} \mathrm{H}+\mathrm{H}$ (ortho-position) is higher than the other two reactions by $0.6-0.7 \mathrm{kcal} / \mathrm{mol}$ as shown in Fig.1, resulting in a 1.22 times $(\exp (0.6 \times 4.1868 \times 1000 / 8.314 / 1500))$ of the rate deviation at $1500 \mathrm{~K}$. This means that the other 0.86 times of the rate deviation come from the orientation hindrance introduced by the $\mathrm{C}_{2} \mathrm{H}$ chain. The $\mathrm{H}$ abstraction reaction is also slightly sensitive to the type of surface site, as illustrated by Fig.6 (b). If one side of the $\mathrm{H}-\mathrm{C}$ bond is the armchair surface site, the corresponding reaction rate coefficient is the lowest compared with that on free-edge and zig-zag surface site, which is in agreement with the study by Semenikhin et al. [42] Here, the rate coefficient of reaction $\mathrm{A}_{3}+\mathrm{H} \rightarrow \mathrm{P} 1-\mathrm{CS} 1+\mathrm{H}_{2}$ is lower than other reactions by at least 1.42 time at $1500 \mathrm{~K}$. It should be noted that the barrier height difference of $0.6-0.7 \mathrm{kcal} / \mathrm{mol}$ is less than half of the accuracy of CBS-QB3 method [48]. But similar conclusions are also obtained by the study of Semenikhin et al [42], where the rate constant of $\mathrm{H}$ abstraction reaction from zigzag site is $37-42 \%$ higher than that from armchair site based on the G3(MP2,CC) calculation.

Compared with $\mathrm{H}$ abstraction reactions, the $\mathrm{C}_{2} \mathrm{H}_{2}$ addition reaction is more sensitive to the site position and site type. If the active $\mathrm{C}$ atom is located at the ortho-position relative to the $\mathrm{C}_{2} \mathrm{H}$ substituent, the rate coefficient of 
$\mathrm{C}_{2} \mathrm{H}_{2}$ addition reactions (N2-CS4+ $\mathrm{C}_{2} \mathrm{H}_{2} \rightarrow \mathrm{N} 2-\mathrm{CS} 11$ and $\mathrm{N} 2-\mathrm{CS} 10+\mathrm{C}_{2} \mathrm{H}_{2} \rightarrow \mathrm{N} 2-\mathrm{CS} 17$ ) are not competitive with other similar reactions, although the formed N2-CS11 and N2-CS18 species can lead to the formation of a new benzene ring (anthracene and phenanthrene). As shown in Fig.6 (c), the rate coefficients of N2-CS10+C $2 \mathrm{H}_{2} \rightarrow \mathrm{N} 2-$ $\mathrm{CS} 17\left(\mathrm{~N} 2-\mathrm{CS} 4+\mathrm{C}_{2} \mathrm{H}_{2} \rightarrow \mathrm{N} 2-\mathrm{CS} 11\right)$ are lower than that of $\mathrm{N} 2-\mathrm{CS} 5+\mathrm{C}_{2} \mathrm{H}_{2} \rightarrow \mathrm{N} 2-\mathrm{CS} 12, \mathrm{~N} 2-\mathrm{CS} 6+\mathrm{C}_{2} \mathrm{H}_{2} \rightarrow \mathrm{N} 2-\mathrm{CS} 13$, $\mathrm{N} 2-\mathrm{CS} 7+\mathrm{C}_{2} \mathrm{H}_{2} \rightarrow \mathrm{N} 2-\mathrm{CS} 14, \mathrm{~N} 2-\mathrm{CS} 8+\mathrm{C}_{2} \mathrm{H}_{2} \rightarrow \mathrm{N} 2-\mathrm{CS} 15$, and N2-CS9+ $\mathrm{C}_{2} \mathrm{H}_{2} \rightarrow \mathrm{N} 2-\mathrm{CS} 16$ by a factor of 1.66 (1.18), 1.53 (1.09), 5.05 (3.60), 6.17 (4.39), and 1.76 (1.25), respectively. The $\mathrm{C}_{2} \mathrm{H}_{2}$ attack on the active $\mathrm{C}$ atom with two free-edge surface sites is preferred due to the relatively low energy barrier $(4.3 \mathrm{kcal} / \mathrm{mol})$. Examples of this include the reactions of P2-CS1 $+\mathrm{C}_{2} \mathrm{H}_{2} \rightarrow \mathrm{P} 2-\mathrm{CS} 2$ and $\mathrm{P} 3-\mathrm{CS} 1+\mathrm{C}_{2} \mathrm{H}_{2} \rightarrow \mathrm{P} 3-\mathrm{CS} 2$ found in Fig.6 (d). The rate coefficient of the addition of $\mathrm{C}_{2} \mathrm{H}_{2}$ to $\mathrm{P} 1-\mathrm{CS} 1$ species is the lowest due to the relatively high energy barrier $(7.3 \mathrm{kcal} / \mathrm{mol}) \mathrm{among}$ all investigated $\mathrm{C}_{2} \mathrm{H}_{2}$ addition reactions. This means that PAHs that are fully constituted by benzene rings are not the preferred product in the HACA-based mass growth process, and the corresponding isomers with the 5membered ring are more likely to form especially for large PAHs.

Table 2. Reaction rate parameters in the form of $\mathrm{AT}^{\mathrm{n}} \exp (-\mathrm{E} / \mathrm{RT})$, the units are $\mathrm{s}^{-1}, \mathrm{~cm}^{3} \mathrm{~mol}^{-1} \mathrm{~s}^{-1}$ and kcal.

\begin{tabular}{|c|c|c|c|c|c|c|c|}
\hline $\operatorname{Re}$ & $\mathrm{A}$ & $\mathrm{n}$ & $\mathrm{E}$ & Reaction & $\mathrm{A}$ & $\mathrm{n}$ & $\mathrm{E}$ \\
\hline \multicolumn{8}{|c|}{ Benzene $\left(\mathrm{A}_{1}\right) \rightarrow$ Naphthalene $\left(\mathrm{A}_{2}\right)$} \\
\hline$\overline{\mathrm{ne}+\mathrm{H} \rightarrow \mathrm{B}-\mathrm{C}}$ & $75 \times 10^{8}$ & 1.9100 & 15.61 & B-CS12+H $\rightarrow$ Benzene $+\mathrm{H}$ & $1.22 \times 10^{4}$ & 2.6550 & 8.54 \\
\hline $\mathrm{B}-\mathrm{CS} 12+\mathrm{C}_{2} \mathrm{H}_{2} \rightarrow \mathrm{B}-\mathrm{CS} 13$ & $8.75 \times 10^{4}$ & 2.5040 & 4.65 & $\mathrm{~B}-\mathrm{CS} 13 \rightarrow \mathrm{B}-\mathrm{CS} 12+\mathrm{C}_{2} \mathrm{H}_{2}$ & $8.36 \times 10^{14}$ & 0.3036 & 42.66 \\
\hline $\mathrm{B}-\mathrm{CS} 13 \rightarrow \mathrm{B}-\mathrm{CS} 14+\mathrm{H}$ & $7.63 \times 10^{11}$ & 0.8021 & 35.30 & $\mathrm{~B}-\mathrm{CS} 14+\mathrm{H} \rightarrow \mathrm{B}-\mathrm{CS} 13$ & $5.26 \times 10^{8}$ & 1.5610 & 5.73 \\
\hline $\mathrm{B}-\mathrm{CS} 13 \rightarrow \mathrm{B}-\mathrm{CS} 15$ & $9.99 \times 10^{7}$ & 1.3140 & 21.44 & $\mathrm{~B}-\mathrm{CS} 15 \rightarrow \mathrm{B}-\mathrm{CS} 13$ & $6.12 \times 10^{7}$ & 1.3980 & 18.90 \\
\hline $\mathrm{B}-\mathrm{CS} 15+\mathrm{C}_{2} \mathrm{H}_{2} \rightarrow \mathrm{B}-\mathrm{CS} 16$ & $7.02 \times 10^{3}$ & 2.5630 & 2.92 & $\mathrm{~B}-\mathrm{CS} 16 \rightarrow \mathrm{B}-\mathrm{CS} 15+\mathrm{C}_{2} \mathrm{H}_{2}$ & $2.21 \times 10^{14}$ & 0.2209 & 40.52 \\
\hline $\mathrm{B}-\mathrm{CS} 16 \rightarrow \mathrm{B}-\mathrm{CS} 17$ & $.57 \times 10^{11}$ & 0.3574 & 0.39 & $\mathrm{~B}-\mathrm{CS} 17 \rightarrow \mathrm{B}-\mathrm{CS} 16$ & $3.78 \times 10^{12}$ & 0.0149 & 2.19 \\
\hline $\mathrm{B}-\mathrm{CS} 17 \rightarrow \mathrm{B}-\mathrm{CS} 18$ & $1.88 \times 10^{11}$ & 0.2239 & 0.25 & $\mathrm{~B}-\mathrm{CS} 18 \rightarrow \mathrm{B}-\mathrm{CS} 17$ & $4.85 \times 10^{12}$ & 0.4702 & 51.08 \\
\hline $\mathrm{B}-\mathrm{CS} 18 \rightarrow \mathrm{A}_{2}+\mathrm{H}$ & $2.30 \times 10^{11}$ & 0.7058 & 25.00 & $\mathrm{~A}_{2}+\mathrm{H} \rightarrow \mathrm{B}-\mathrm{CS} 18$ & $9.08 \mathrm{x}$ & 1.5520 & 4.59 \\
\hline $4+\mathrm{H} \rightarrow \mathrm{B}-\mathrm{CS} 3+\mathrm{H}_{2}$ & $6.57 \times 10^{7}$ & 1.90 & 15.39 & $\mathrm{~B}-\mathrm{CS} 3+\mathrm{H}_{2} \rightarrow \mathrm{B}-\mathrm{CS} 14+\mathrm{H}$ & $1.29 \mathrm{x}$ & 2.6620 & 7.88 \\
\hline $\mathrm{B}-\mathrm{CS} 3+\mathrm{C}_{2} \mathrm{H}_{2} \rightarrow \mathrm{B}-\mathrm{CS} 9$ & $9.32 \times 10^{4}$ & 2.5860 & 3.72 & $\mathrm{~B}-\mathrm{CS} 9 \rightarrow \mathrm{B}-\mathrm{CS} 3+\mathrm{C}_{2} \mathrm{H}_{2}$ & $5.28 \times 10^{14}$ & 0.3253 & 40.78 \\
\hline $\mathrm{B}-\mathrm{CS} 9 \rightarrow \mathrm{B}-\mathrm{CS} 10+\mathrm{H}$ & $5.94 \times 10^{11}$ & 0.8054 & 33.64 & $\mathrm{~B}-\mathrm{CS} 10+\mathrm{H} \rightarrow \mathrm{B}-\mathrm{CS} 9$ & $1.11 \times 10^{9}$ & 1.5600 & 5.72 \\
\hline $\mathrm{B}-\mathrm{CS} 14+\mathrm{H} \rightarrow \mathrm{B}-\mathrm{CS} 2+\mathrm{H}_{2}$ & $6.06 \times 10^{7}$ & 1.9040 & 15.25 & $\mathrm{~B}-\mathrm{CS} 2+\mathrm{H}_{2} \rightarrow \mathrm{B}-\mathrm{CS} 14+\mathrm{H}$ & $1.20 \times 10^{4}$ & 2.6620 & 7.97 \\
\hline $\mathrm{B}-\mathrm{CS} 2+\mathrm{C}_{2} \mathrm{H}_{2} \rightarrow \mathrm{B}-\mathrm{CS} 7$ & $6.98 \times 10^{4}$ & 2.6340 & 1.83 & $\mathrm{~B}-\mathrm{CS} 7 \rightarrow \mathrm{B}-\mathrm{CS} 2+\mathrm{C}_{2} \mathrm{H}_{2}$ & $3.11 \times 10^{14}$ & 0.3803 & 41.04 \\
\hline $\mathrm{B}-\mathrm{CS} 7 \rightarrow \mathrm{B}-\mathrm{CS} 8+\mathrm{H}$ & $3.94 \times 10^{11}$ & 0.8174 & 33.76 & $3+\mathrm{H} \rightarrow \mathrm{B}-\mathrm{CS} 7$ & $4.76 \times 10^{8}$ & 1.5670 & 5.59 \\
\hline$+\mathrm{H} \rightarrow$ & $7.55 \times 10^{7}$ & 1.8830 & 16.11 & $1+\mathrm{H}_{2} \rightarrow \mathrm{B}-\mathrm{CS} 14+\mathrm{H}$ & $1.23 \times 10^{4}$ & 2.6600 & 7.52 \\
\hline$-\mathrm{C}_{2} \mathrm{H}_{2}-$ & $2.02 \times 10^{4}$ & 2.5720 & 3.13 & $\rightarrow \mathrm{B}-\mathrm{CS} 1+\mathrm{C}_{2} \mathrm{H}_{2}$ & $1.96 \times 10^{14}$ & 0.2971 & 41.48 \\
\hline$\rightarrow \mathrm{B}-\mathrm{C}$ & $6.12 \times 10^{11}$ & 0.8095 & 36.04 & $1+\mathrm{H} \rightarrow \mathrm{B}-\mathrm{CS} 4$ & $4.62 \times 10^{8}$ & 1.5470 & 6.45 \\
\hline $\mathrm{B}-\mathrm{CS} 4 \rightarrow \mathrm{B}-\mathrm{CS} 5$ & $1.34 \times 10^{12}$ & 0.1289 & 3.71 & $\mathrm{~B}-\mathrm{CS} 5 \rightarrow \mathrm{B}-\mathrm{CS} 4$ & $2.74 \times 10^{12}$ & 0.0076 & 2.44 \\
\hline$\rightarrow \mathrm{B}-\mathrm{C}$ & $4.82 \times 10^{11}$ & 0.8099 & 34.60 & $1+\mathrm{H} \rightarrow \mathrm{B}-\mathrm{CS} 5$ & $4.62 \times 10^{8}$ & 1.5470 & 6.45 \\
\hline$\rightarrow$ B-CS6 & $8.68 \times 10^{11}$ & 0.0285 & 4.55 & $\mathrm{~B}-\mathrm{CS} 6 \rightarrow \mathrm{B}-\mathrm{CS} 5$ & $2.85 \times 10^{13}$ & 0.4022 & 57.24 \\
\hline$-\mathrm{H} \rightarrow$ & $1.00 \times 10^{14}$ & 0 & 0 & & & & \\
\hline \multicolumn{8}{|c|}{ Naphthalene $\left(\mathrm{A}_{2}\right) \rightarrow$ Phenanthrene $\left(\mathrm{A}_{3}\right)$} \\
\hline$\overline{\mathrm{A}_{2}+\mathrm{H}}$ & $8.16 \times 10^{9}$ & 1.5676 & 17.4 & $\mathrm{~N} 2-\mathrm{C}$ & & & 10.2 \\
\hline $\mathrm{N} 2-\mathrm{CS} 1+\mathrm{C}_{2} \mathrm{H}_{2} \rightarrow \mathrm{N} 2-\mathrm{CS} 2$ & $1.04 \times 10^{5}$ & 2.5125 & 4.3 & $\mathrm{~N} 2-\mathrm{CS} 2 \rightarrow \mathrm{N} 2-\mathrm{CS} 1+\mathrm{C}_{2} \mathrm{H}_{2}$ & $2.23 \times 10^{13}$ & 0.5379 & 41.0 \\
\hline $\mathrm{N} 2-\mathrm{CS} 2 \rightarrow \mathrm{N} 2-\mathrm{CS} 37$ & $2.30 \times 10^{11}$ & 0.2584 & 27.5 & $\mathrm{~N} 2-\mathrm{CS} 37 \rightarrow \mathrm{N} 2-\mathrm{CS} 2$ & $2.55 \times 10^{11}$ & 0.3916 & 27.1 \\
\hline $\mathrm{N} 2-\mathrm{CS} 2 \rightarrow \mathrm{N} 2-\mathrm{CS} 3+\mathrm{H}$ & $2.75 \times 10^{10}$ & 0.9966 & 37.8 & $\mathrm{~N} 2-\mathrm{CS} 3+\mathrm{H} \rightarrow \mathrm{N} 2-\mathrm{CS} 2$ & $5.06 \times 10^{9}$ & 1.2681 & 4.7 \\
\hline $\mathrm{N} 2-\mathrm{CS} 37+\mathrm{C}_{2} \mathrm{H}_{2} \rightarrow \mathrm{N} 2-\mathrm{CS} 38$ & $6.20 \times 10^{4}$ & 2.2527 & 7.2 & $\mathrm{~N} 2-\mathrm{CS} 38 \rightarrow \mathrm{N} 2-\mathrm{CS} 37+\mathrm{C}_{2} \mathrm{H}_{2}$ & $6.04 \times 10^{13}$ & 0.3680 & 37.0 \\
\hline
\end{tabular}




\begin{tabular}{|c|c|c|c|c|c|c|c|}
\hline $\mathrm{N} 2-\mathrm{CS} 38 \rightarrow \mathrm{N} 2-\mathrm{CS} 41$ & $2.63 \times 10^{12}$ & 1161 & 1.7 & $\mathrm{~N} 2-\mathrm{CS} 41 \rightarrow \mathrm{N} 2-\mathrm{CS} 38$ & $2.76 \times 10^{12}$ & 0.0646 & 1.1 \\
\hline $\mathrm{N} 2-\mathrm{CS} 41 \rightarrow \mathrm{N} 2-\mathrm{CS} 42$ & $1.23 \times 10^{12}$ & 0.0235 & 0.3 & $\mathrm{~N} 2-\mathrm{CS} 42 \rightarrow \mathrm{N} 2-\mathrm{CS} 41$ & $2.20 \times 10^{12}$ & 0.4947 & \\
\hline $2-\mathrm{CS} 38 \rightarrow \mathrm{N} 2-\mathrm{CS} 39$ & $6.69 \times 10^{11}$ & 1561 & 12.5 & $\mathrm{~N} 2-\mathrm{CS} 39 \rightarrow \mathrm{N} 2-\mathrm{CS} 38$ & $8.10 \times 10^{11}$ & 0.4987 & \\
\hline $\mathrm{N} 2-\mathrm{CS} 39 \rightarrow \mathrm{N} 2-\mathrm{CS} 40+\mathrm{H}$ & $3.01 \times 10^{11}$ & 7246 & 28.5 & $\mathrm{~N} 2-\mathrm{CS} 40+\mathrm{H} \rightarrow \mathrm{N} 2-\mathrm{CS} 39$ & $3.16 \times 10^{7}$ & .2018 & 8 \\
\hline $\mathrm{N} 2-\mathrm{CS} 42 \rightarrow \mathrm{A}_{3}+\mathrm{H}$ & $2.31 \times 10^{11}$ & 0.6710 & 27.4 & $\mathrm{~A}_{3}+\mathrm{H} \rightarrow \mathrm{N} 2-\mathrm{CS} 42$ & $6.38 \times 10^{9}$ & .1534 & .5 \\
\hline $\mathrm{J} 1-\mathrm{CS} 37 \rightarrow \mathrm{A}_{3}+\mathrm{H}$ & $01 \times 10^{11}$ & 0.7809 & 28.5 & $\mathrm{~A}_{3}+\mathrm{H} \rightarrow \mathrm{N} 1-\mathrm{CS} 37$ & $7.11 \times 10^{9}$ & .1466 & .4 \\
\hline $\mathrm{N} 1-\mathrm{CS} 36 \rightarrow \mathrm{N} 1-\mathrm{CS} 37$ & $.38 \times 10^{12}$ & 0 & 0.2 & $\mathrm{~N} 1-\mathrm{CS} 37 \rightarrow \mathrm{N} 1-\mathrm{CS} 36$ & $1.80 \times 10^{12}$ & 0.5197 & 53.9 \\
\hline $\mathrm{J} 1-\mathrm{CS} 35 \rightarrow \mathrm{N} 1-\mathrm{CS} 36$ & $.90 \times 10^{12}$ & 0 & .1 & $\mathrm{~J} 1-\mathrm{CS} 36 \rightarrow \mathrm{N} 1-\mathrm{CS} 35$ & $4.54 \times 10^{9}$ & 0.8206 & 8 \\
\hline $\mathrm{J} 1-\mathrm{CS} 34+\mathrm{C}_{2} \mathrm{H}_{2} \rightarrow \mathrm{N} 1-\mathrm{CS} 35$ & $3.06 \times 10^{2}$ & 3.2433 & 5.4 & $\mathrm{~N} 1-\mathrm{CS} 35 \rightarrow \mathrm{N} 1-\mathrm{CS} 34+\mathrm{C}_{2} \mathrm{H}_{2}$ & $9.18 \times 10^{13}$ & 0.2837 & 40.2 \\
\hline $\mathrm{J} 1-\mathrm{CS} 33 \rightarrow \mathrm{N} 1-\mathrm{CS} 34$ & $.61 \times 10^{11}$ & 0.2975 & 26.6 & $\mathrm{~N} 1-\mathrm{CS} 34 \rightarrow \mathrm{N} 1-\mathrm{CS} 33$ & $3.27 \times 10^{9}$ & 1.3516 & 5.5 \\
\hline $\mathrm{N} 1-\mathrm{CS} 2 \rightarrow \mathrm{N} 1-\mathrm{CS} 33$ & $.19 \times 10^{12}$ & 0.1738 & 3.6 & $\mathrm{~N} 1-\mathrm{CS} 33 \rightarrow \mathrm{N} 1-\mathrm{CS} 2$ & $1.30 \times 10^{12}$ & 0.1045 & 2.6 \\
\hline $\mathrm{J} 1-\mathrm{CS} 2 \rightarrow \mathrm{N} 1-\mathrm{CS} 5+\mathrm{H}$ & $3.57 \times 10^{11}$ & 0.8706 & 38.2 & $\mathrm{~N} 1-\mathrm{CS} 5+\mathrm{H} \rightarrow \mathrm{N} 1-\mathrm{CS} 2$ & $8.99 \times 10^{9}$ & 1.2034 & 5.2 \\
\hline $\mathrm{J} 1-\mathrm{CS} 33 \rightarrow \mathrm{N} 1-\mathrm{CS} 5+\mathrm{H}$ & $.34 \times 10^{11}$ & 0.8702 & 37.2 & $\mathrm{~N} 1-\mathrm{CS} 5+\mathrm{H} \rightarrow \mathrm{N} 1-\mathrm{CS} 33$ & $8.99 \times 10^{9}$ & 1.2034 & 5.2 \\
\hline $\mathrm{J} 1-\mathrm{CS} 3 \rightarrow \mathrm{N} 1-\mathrm{CS} 4\left(\mathrm{~A}_{2} \mathrm{R}_{5}\right)$ & $1.27 \times 10^{11}$ & 0.8322 & 27.9 & $\begin{array}{l}\mathrm{S} 4\left(\mathrm{~A}_{2} \mathrm{R}_{5}\right)+\mathrm{H} \rightarrow \\
\mathrm{S} 3\end{array}$ & & 1.2534 & 4.5 \\
\hline $\mathrm{S} 2 \rightarrow \mathrm{N} 1-\mathrm{CS} 3$ & $\mathrm{x} 10^{9}$ & 0.7858 & 16.1 & $3 \rightarrow \mathrm{N} 1-\mathrm{CS} 2$ & $0^{12}$ & 175 & 2.5 \\
\hline $11-\mathrm{CS} 1+\mathrm{C}_{2} \mathrm{H}_{2} \rightarrow \mathrm{N} 1-\mathrm{CS} 2$ & $3.70 \times 10^{4}$ & 2.5519 & 4.6 & $2 \rightarrow \mathrm{N} 1-\mathrm{CS} 1+\mathrm{C}_{2} \mathrm{H}_{2}$ & & 246 & 41.0 \\
\hline $\mathrm{I}_{2}+\mathrm{H} \rightarrow \mathrm{N} 1-\mathrm{CS} 1+\mathrm{H}_{2}$ & $9.12 \times 10^{9}$ & 1.5489 & 17.7 & $\mathrm{~S} 1+\mathrm{H}_{2} \rightarrow \mathrm{A}_{2}+\mathrm{H}$ & $7.02 \times 10^{6}$ & 1.9134 & 10.4 \\
\hline $11-\mathrm{CS} 32 \rightarrow \mathrm{N} 2-\mathrm{CS} 35+\mathrm{H}$ & $1.83 \times 10^{11}$ & 0.7991 & 31.3 & $\mathrm{~N} 2-\mathrm{CS} 35+\mathrm{H} \rightarrow \mathrm{N} 1-\mathrm{CS} 32$ & $3.81 \times 10^{9}$ & 1.2164 & 4.2 \\
\hline $11-\mathrm{CS} 31 \rightarrow \mathrm{N} 1-\mathrm{CS} 32$ & $6.22 \times 10^{11}$ & 0.1087 & 14.3 & $\mathrm{~S} 32 \rightarrow \mathrm{N} 1-\mathrm{CS} 31$ & $8.39 \times 10^{11}$ & 0.4962 & 35.2 \\
\hline 31 & $10^{11}$ & & 2.4 & & & & 3.4 \\
\hline $11-\mathrm{CS} 16 \rightarrow \mathrm{N} 1-\mathrm{CS} 23+\mathrm{H}$ & $9.73 \times 10^{10}$ & 0.9619 & 37.0 & $23+\mathrm{H} \rightarrow \mathrm{N} 1-\mathrm{CS} 16$ & & & 5.0 \\
\hline $11-\mathrm{CS} 9+\mathrm{C}_{2} \mathrm{H}_{2} \rightarrow \mathrm{N} 1-\mathrm{CS} 16$ & $4.72 \times 10^{4}$ & 2.5230 & 4.5 & $16 \rightarrow \mathrm{N} 1-\mathrm{CS} 9+\mathrm{C}_{2} \mathrm{H}_{2}$ & & 018 & 39.8 \\
\hline $\mathrm{S} 5+\mathrm{H} \rightarrow \mathrm{N} 1-\mathrm{CS} 9+\mathrm{H}_{2}$ & $10^{9}$ & 1.5498 & 17.9 & $\mathrm{~S} 9+\mathrm{H}_{2} \rightarrow \mathrm{N} 1-\mathrm{CS} 5+\mathrm{H}$ & $10^{6}$ & 051 & 10.2 \\
\hline $\mathrm{S} 5+\mathrm{H} \rightarrow \mathrm{N} 1-\mathrm{CS} 10+\mathrm{H}_{2}$ & $10^{9}$ & 1.5603 & 17.6 & $\mathrm{~S} 10+\mathrm{H}_{2} \rightarrow \mathrm{N} 1-\mathrm{CS} 5+\mathrm{H}$ & $10^{6}$ & 110 & 10.2 \\
\hline $11-\mathrm{CS} 10+\mathrm{C}_{2} \mathrm{H}_{2} \rightarrow \mathrm{N} 1-\mathrm{CS} 17$ & $3.54 \times 10^{5}$ & 2.4971 & 4.2 & $\mathrm{~N} 1-\mathrm{CS} 17 \rightarrow \mathrm{N} 1-\mathrm{CS} 10+\mathrm{C}_{2} \mathrm{H}_{2}$ & $3.12 \times 10^{14}$ & 612 & 42.9 \\
\hline $11-\mathrm{CS} 17 \rightarrow \mathrm{N} 2-\mathrm{CS} 20+\mathrm{H}$ & $2.91 \times 10^{11}$ & 0.9823 & 39.6 & $1-\mathrm{CS} 17$ & $10^{9}$ & 793 & 4.5 \\
\hline$+\mathrm{H} \rightarrow \mathrm{N} 1-\mathrm{CS} 11+\mathrm{H}_{2}$ & $10^{9}$ & 1.5721 & 17.5 & $11+\mathrm{H}_{2} \rightarrow \mathrm{N} 1-\mathrm{CS} 5+\mathrm{H}$ & & 286 & 10.2 \\
\hline $1+\mathrm{C}_{2} \mathrm{H}_{2} \rightarrow \mathrm{N} 1-\mathrm{CS} 18$ & $10^{5}$ & 2.4893 & 4.3 & $18 \rightarrow \mathrm{N} 1-\mathrm{CS} 11+\mathrm{C}_{2} \mathrm{H}_{2}$ & 5.3 & 104 & 41.8 \\
\hline$\rightarrow \mathrm{N} 2-\mathrm{CS} 23+\mathrm{H}$ & $10^{11}$ & 1.0097 & 38.6 & $3+\mathrm{H} \rightarrow \mathrm{N} 1-\mathrm{CS} 18$ & $10^{9}$ & 149 & 4.5 \\
\hline $\mathrm{S} 5+\mathrm{H} \rightarrow \mathrm{N} 1-\mathrm{CS} 12+\mathrm{H}_{2}$ & $10^{8}$ & 1.5466 & 19.5 & $2+\mathrm{H}_{2} \rightarrow \mathrm{N} 1-\mathrm{CS} 5+\mathrm{H}$ & & 90 & 11.8 \\
\hline $11-\mathrm{CS} 12+\mathrm{C}_{2} \mathrm{H}_{2} \rightarrow \mathrm{N} 1-\mathrm{CS} 19$ & $2.36 \times 10^{4}$ & 2.4781 & 6.7 & $\mathrm{~N} 1-\mathrm{CS} 19 \rightarrow \mathrm{N} 1-\mathrm{CS} 12+\mathrm{C}_{2} \mathrm{H}_{2}$ & $10^{11}$ & 366 & 33.8 \\
\hline $1-\mathrm{CS} 19 \rightarrow \mathrm{N} 1-\mathrm{CS} 26+\mathrm{H}$ & $9.03 \times 10^{10}$ & 0.9797 & 35.0 & $6+\mathrm{H} \rightarrow \mathrm{N} 1-\mathrm{CS} 19$ & $10^{9}$ & 456 & 4.8 \\
\hline $\mathrm{S} 5+\mathrm{H} \rightarrow \mathrm{N} 1-\mathrm{CS} 6+\mathrm{H}_{2}$ & $1.35 \times 10^{9}$ & 1.5479 & 18.6 & $-\mathrm{CS} 5+\mathrm{H}$ & & 38 & 10.3 \\
\hline $\mathrm{CS} 13$ & $0^{5}$ & 2.2917 & 3.4 & $\mathrm{~S} 6+\mathrm{C}_{2} \mathrm{H}_{2}$ & & & 42.4 \\
\hline$\rightarrow \mathrm{N} 2-\mathrm{CS} 24+\mathrm{H}$ & $0^{11}$ & 364 & 40.6 & $1-\mathrm{CS} 13$ & & 914 & 4.9 \\
\hline $3 \rightarrow \mathrm{N} 1-\mathrm{CS} 27$ & $2.00 \times 10^{12}$ & 0.1097 & 5.5 & $7 \rightarrow \mathrm{N}$ & $10^{12}$ & 021 & 4.0 \\
\hline $\mathrm{N} 1-\mathrm{CS} 27 \rightarrow \mathrm{N} 2-\mathrm{CS} 24+\mathrm{H}$ & $1.04 \times 10^{11}$ & 1.0355 & 39.1 & $4+\mathrm{H} \rightarrow \mathrm{N} 1-\mathrm{CS} 27$ & $\times 10^{9}$ & 1.2914 & 4.9 \\
\hline $\mathrm{N} 1-\mathrm{CS} 27 \rightarrow \mathrm{N} 1-\mathrm{CS} 20$ & $1.23 \times 10^{12}$ & 0 & 3.7 & $\mathrm{~N} 1-\mathrm{CS} 20 \rightarrow \mathrm{N} 1-\mathrm{CS} 27$ & $8.30 \times 10^{11}$ & 0.0432 & 61.2 \\
\hline $\mathrm{S} 5+\mathrm{H} \rightarrow \mathrm{N} 1-\mathrm{CS} 8+\mathrm{H}_{2}$ & $9.90 \times 10^{5}$ & & 11.6 & $+\mathrm{H}_{2} \rightarrow$ & & 485 & 10.4 \\
\hline $\mathrm{CS} 15$ & $0^{4}$ & & 4.3 & $8+\mathrm{C}_{2} \mathrm{H}_{2}$ & & & 40.1 \\
\hline$\rightarrow \mathrm{N} 1-\mathrm{CS} 22+\mathrm{H}$ & $10^{9}$ & 1.8080 & 37.4 & $2+\mathrm{H} \rightarrow \mathrm{N} 1-\mathrm{CS} 15$ & 7. & 270 & 5.2 \\
\hline $15 \rightarrow \mathrm{N} 1-\mathrm{CS} 28$ & $1.30 \times 10^{10}$ & 1.0820 & 2.7 & $8 \rightarrow \mathrm{N} 1-\mathrm{CS} 15$ & $10^{12}$ & 154 & 3.7 \\
\hline $\mathrm{N} 1-\mathrm{CS} 28 \rightarrow \mathrm{N} 1-\mathrm{CS} 22+\mathrm{H}$ & $3.14 \times 10^{9}$ & 1.8079 & 38.3 & $\mathrm{~S} 22+\mathrm{H} \rightarrow \mathrm{N} 1-\mathrm{CS} 28$ & $\times 10^{9}$ & 1.2270 & 5.2 \\
\hline $\mathrm{S} 28 \rightarrow \mathrm{N} 1-\mathrm{CS} 29$ & $.02 \times 10^{12}$ & 0.0499 & 15.4 & $\mathrm{~N} 1-\mathrm{CS} 29 \rightarrow \mathrm{N} 1-\mathrm{CS} 28$ & $5.27 \times 10^{12}$ & 0.2536 & 32.8 \\
\hline$\rightarrow \mathrm{N} 2-\mathrm{C}$ & $25 \times 10^{11}$ & 0.8359 & 28.4 & $-\mathrm{CS} 29$ & $10^{9}$ & 1.2418 & 4.5 \\
\hline$+\mathrm{H} \rightarrow \mathrm{N} 1-\mathrm{CS} 7+\mathrm{H}_{2}$ & & & 17.7 & $\mathrm{CS} 5+\mathrm{H}$ & & & 10.2 \\
\hline $\mathrm{N} 1-\mathrm{CS} 7+\mathrm{C}_{2} \mathrm{H}_{2} \rightarrow \mathrm{N} 1-\mathrm{CS} 14$ & $3.91 \times 10^{5}$ & 2.4569 & 4.1 & $\mathrm{~N} 1-\mathrm{CS} 14 \rightarrow \mathrm{N} 1-\mathrm{CS} 7+\mathrm{C}_{2} \mathrm{H}_{2}$ & $2.19 \mathrm{x}$ & 0.4591 & 41.5 \\
\hline $\mathrm{N} 1-\mathrm{CS} 14 \rightarrow \mathrm{N} 2-\mathrm{CS} 19+\mathrm{H}$ & $4.35 \times 10^{11}$ & 0.9563 & 38.5 & $\mathrm{~N} 2-\mathrm{CS} 19+\mathrm{H} \rightarrow \mathrm{N} 1-\mathrm{CS} 14$ & $1.36 \times 10^{10}$ & 1.2935 & 4.4 \\
\hline $\mathrm{N} 2-\mathrm{CS} 32 \rightarrow \mathrm{N} 2-\mathrm{CS} 30+\mathrm{H}$ & $1.16 \times 10^{11}$ & 0.8386 & 27.6 & $30+\mathrm{H} \rightarrow \mathrm{N} 2-\mathrm{CS} 32$ & $2.80 \times 10^{9}$ & 1.2400 & 4.8 \\
\hline $\mathrm{N} 2-\mathrm{CS} 31 \rightarrow \mathrm{N} 2-\mathrm{CS} 32$ & $6.33 \times 10^{11}$ & 0.1109 & 16.4 & $\mathrm{~N} 2-\mathrm{CS} 32 \rightarrow \mathrm{N} 2-\mathrm{CS} 31$ & $1.19 \times 10^{12}$ & 0.4469 & 31.8 \\
\hline $3 \rightarrow \mathrm{N} 2-\mathrm{CS} 31$ & $9.82 \times 10^{11}$ & 0.1388 & 2.5 & $\mathrm{~N} 2-\mathrm{CS} 31 \rightarrow \mathrm{N} 2-\mathrm{CS} 13$ & & 0.1629 & 3.5 \\
\hline $\mathrm{N} 2-\mathrm{CS} 12 \rightarrow \mathrm{N} 2-\mathrm{CS} 28$ & $1.05 \times 10^{12}$ & 0.1354 & 2.4 & $\mathrm{~N} 2-\mathrm{CS} 28 \rightarrow \mathrm{N} 2-\mathrm{CS} 12$ & $9.59 \times 10^{11}$ & 0.1802 & 3.4 \\
\hline
\end{tabular}


$\mathrm{N} 2-\mathrm{CS} 28 \rightarrow \mathrm{N} 2-\mathrm{CS} 29$

$\mathrm{N} 2-\mathrm{CS} 13 \rightarrow \mathrm{N} 2-\mathrm{CS} 20+\mathrm{H}$

$\mathrm{N} 2-\mathrm{CS} 31 \rightarrow \mathrm{N} 2-\mathrm{CS} 20+\mathrm{H}$

$\mathrm{N} 2-\mathrm{CS} 6+\mathrm{C}_{2} \mathrm{H}_{2} \rightarrow \mathrm{N} 2-\mathrm{CS} 13$

$\mathrm{N} 2-\mathrm{CS} 3+\mathrm{H} \rightarrow \mathrm{N} 2-\mathrm{CS} 6+\mathrm{H}_{2}$

$\mathrm{N} 2-\mathrm{CS} 3+\mathrm{H} \rightarrow \mathrm{N} 2-\mathrm{CS} 5+\mathrm{H}_{2}$

$\mathrm{N} 2-\mathrm{CS} 5+\mathrm{C}_{2} \mathrm{H}_{2} \rightarrow \mathrm{N} 2-\mathrm{CS} 12$

$\mathrm{N} 2-\mathrm{CS} 12 \rightarrow \mathrm{N} 2-\mathrm{CS} 19+\mathrm{H}$

$\mathrm{N} 2-\mathrm{CS} 28 \rightarrow \mathrm{N} 2-\mathrm{CS} 19+\mathrm{H}$

$\mathrm{N} 2-\mathrm{CS} 29 \rightarrow \mathrm{N} 2-\mathrm{CS} 30+\mathrm{H}$

$\mathrm{N} 2-\mathrm{CS} 3+\mathrm{H} \rightarrow \mathrm{N} 2-\mathrm{CS} 7+\mathrm{H}_{2}$

$\mathrm{N} 2-\mathrm{CS} 7+\mathrm{C}_{2} \mathrm{H}_{2} \rightarrow \mathrm{N} 2-\mathrm{CS} 14$

$\mathrm{N} 2-\mathrm{CS} 14 \rightarrow \mathrm{N} 2-\mathrm{CS} 21+\mathrm{H}$

$\mathrm{N} 2-\mathrm{CS} 3+\mathrm{H} \rightarrow \mathrm{N} 2-\mathrm{CS} 8+\mathrm{H}_{2}$

$\mathrm{N} 2-\mathrm{CS} 8+\mathrm{C}_{2} \mathrm{H}_{2} \rightarrow \mathrm{N} 2-\mathrm{CS} 15$

$\mathrm{N} 2-\mathrm{CS} 15 \rightarrow \mathrm{N} 2-\mathrm{CS} 22+\mathrm{H}$

$\mathrm{N} 2-\mathrm{CS} 3+\mathrm{H} \rightarrow \mathrm{N} 2-\mathrm{CS} 9+\mathrm{H}_{2}$

$\mathrm{N} 2-\mathrm{CS} 9+\mathrm{C}_{2} \mathrm{H}_{2} \rightarrow \mathrm{N} 2-\mathrm{CS} 16$

$\mathrm{N} 2-\mathrm{CS} 16 \rightarrow \mathrm{N} 2-\mathrm{CS} 23+\mathrm{H}$

$\mathrm{N} 2-\mathrm{CS} 16 \rightarrow \mathrm{N} 2-\mathrm{CS} 33$

$\mathrm{N} 2-\mathrm{CS} 33 \rightarrow \mathrm{N} 2-\mathrm{CS} 23+\mathrm{H}$

$\mathrm{N} 2-\mathrm{CS} 33 \rightarrow \mathrm{N} 2-\mathrm{CS} 34$

$\mathrm{N} 2-\mathrm{CS} 34 \rightarrow \mathrm{N} 2-\mathrm{CS} 35+\mathrm{H}$

$\mathrm{N} 2-\mathrm{CS} 3+\mathrm{H} \rightarrow \mathrm{N} 2-\mathrm{CS} 10+\mathrm{H}_{2}$

$\mathrm{N} 2-\mathrm{CS} 10+\mathrm{C}_{2} \mathrm{H}_{2} \rightarrow \mathrm{N} 2-\mathrm{CS} 17$

$\mathrm{N} 2-\mathrm{CS} 17 \rightarrow \mathrm{N} 2-\mathrm{CS} 36$

$\mathrm{N} 2-\mathrm{CS} 36 \rightarrow \mathrm{N} 2-\mathrm{CS} 35+\mathrm{H}$

$\mathrm{N} 2-\mathrm{CS} 17 \rightarrow \mathrm{N} 2-\mathrm{CS} 24+\mathrm{H}$

$\mathrm{N} 2-\mathrm{CS} 17 \rightarrow \mathrm{N} 2-\mathrm{CS} 43$

$\mathrm{N} 2-\mathrm{CS} 43 \rightarrow \mathrm{N} 2-\mathrm{CS} 24+\mathrm{H}$

$\mathrm{N} 2-\mathrm{CS} 43 \rightarrow \mathrm{N} 2-\mathrm{CS} 44$

$\mathrm{N} 2-\mathrm{CS} 3+\mathrm{H} \rightarrow \mathrm{N} 2-\mathrm{CS} 4+\mathrm{H}_{2}$

$\mathrm{N} 2-\mathrm{CS} 4+\mathrm{C}_{2} \mathrm{H}_{2} \rightarrow \mathrm{N} 2-\mathrm{CS} 11$

$\mathrm{N} 2-\mathrm{CS} 11 \rightarrow \mathrm{N} 2-\mathrm{CS} 25$

$\mathrm{N} 2-\mathrm{CS} 25 \rightarrow \mathrm{N} 2-\mathrm{CS} 26$

$\mathrm{N} 2-\mathrm{CS} 11 \rightarrow \mathrm{N} 2-\mathrm{CS} 18+\mathrm{H}$

$\mathrm{N} 2-\mathrm{CS} 25 \rightarrow \mathrm{N} 2-\mathrm{CS} 18+\mathrm{H}$

$\mathrm{N} 2-\mathrm{CS} 26+\mathrm{H} \rightarrow \mathrm{N} 2-\mathrm{CS} 27^{\mathrm{a}}$

$\mathrm{N} 1-\mathrm{CS} 20+\mathrm{H} \rightarrow \mathrm{A}_{3}{ }^{\mathrm{a}}$
$5.53 \times 10$

$1.00 \times 10^{11}$

0.1168

$1.58 \times 10^{11}$

0.9848

0.1002

$4.92 \times 10^{4}$

2.5227

$1.01 \times 10^{9}$

$1.02 \times 10^{9}$

$5.64 \times 10^{4}$

$2.46 \times 10^{7}$

$2.32 \times 10^{7}$

$1.37 \times 10^{11}$

$9.93 \times 10^{8}$

$2.56 \times 10^{5}$

$6.70 \times 10^{10}$

$9.24 \times 10^{8}$

$2.90 \times 10^{5}$

$2.46 \times 10^{10}$

$1.05 \times 10^{9}$

$5.30 \times 10^{4}$

$1.80 \times 10^{11}$

$1.37 \times 10^{12}$

$1.16 \times 10^{11}$

$6.03 \times 10^{11}$

$2.36 \times 10^{11}$

$1.30 \times 10^{9}$

$2.98 \times 10^{4}$

$1.68 \times 10^{12}$

$1.62 \times 10^{11}$

$1.92 \times 10^{11}$

$4.04 \times 10^{12}$

$1.69 \times 10^{11}$

$8.03 \times 10^{11}$

$1.23 \times 10^{9}$

$1.14 \times 10^{5}$

$2.68 \times 10^{12}$

$1.16 \times 10^{12}$

$2.76 \times 10^{10}$

$2.91 \times 10^{10}$

$1.00 \times 10^{14}$

$1.00 \times 10^{14}$
$15640-17.8$

1.5589

$\begin{array}{ll}1.5589 & 17.8\end{array}$

$2.5102 \quad 4.4$

$2.0707 \quad 37.3$

$2.0645 \quad 38.4$

\begin{tabular}{ll}
$0.8248 \quad 28.2$ \\
\hline
\end{tabular}

$\begin{array}{ll}1.5737 & 17.5\end{array}$

$2.4510 \quad 4.3$

$1.0143 \quad 39.0$

$1.5842 \quad 17.5$

$2.4567 \quad 4.2$

$\begin{array}{ll}1.0074 & 37.8\end{array}$

$\begin{array}{ll}1.5548 & 17.9\end{array}$

2.5267

0.9365

0.1278

0.9412

0.1068

0.7638

1.5400

2.5282

0

0.8140

0.9906

0

0.9895

0

1.5554

2.3544

0

0

1.1079

1.0998

0

0

4.5

18.6

3.6

3.6

5.0

38.7
$\mathrm{N} 2-\mathrm{CS} 29 \rightarrow \mathrm{N} 2-\mathrm{CS} 28$

$\mathrm{N} 2-\mathrm{CS} 20+\mathrm{H} \rightarrow \mathrm{N} 2-\mathrm{CS} 13$

$\mathrm{N} 2-\mathrm{CS} 20+\mathrm{H} \rightarrow \mathrm{N} 2-\mathrm{CS} 31$

$\mathrm{N} 2-\mathrm{CS} 13 \rightarrow \mathrm{N} 2-\mathrm{CS} 6+\mathrm{C}_{2} \mathrm{H}_{2}$

$\mathrm{N} 2-\mathrm{CS} 6+\mathrm{H}_{2} \rightarrow \mathrm{N} 2-\mathrm{CS} 3+\mathrm{H}$

$\mathrm{N} 2-\mathrm{CS} 5+\mathrm{H}_{2} \rightarrow \mathrm{N} 2-\mathrm{CS} 3+\mathrm{H}$

$\mathrm{N} 2-\mathrm{CS} 12 \rightarrow \mathrm{N} 2-\mathrm{CS} 5+\mathrm{C}_{2} \mathrm{H}_{2}$

$\mathrm{N} 2-\mathrm{CS} 19+\mathrm{H} \rightarrow \mathrm{N} 2-\mathrm{CS} 12$

$\mathrm{N} 2-\mathrm{CS} 19+\mathrm{H} \rightarrow \mathrm{N} 2-\mathrm{CS} 28$

$\mathrm{N} 2-\mathrm{CS} 30+\mathrm{H} \rightarrow \mathrm{N} 2-\mathrm{CS} 29$

$\mathrm{N} 2-\mathrm{CS} 7+\mathrm{H}_{2} \rightarrow \mathrm{N} 2-\mathrm{CS} 3+\mathrm{H}$

$\mathrm{N} 2-\mathrm{CS} 14 \rightarrow \mathrm{N} 2-\mathrm{CS} 7+\mathrm{C}_{2} \mathrm{H}_{2}$

$\mathrm{N} 2-\mathrm{CS} 21+\mathrm{H} \rightarrow \mathrm{N} 2-\mathrm{CS} 14$

$\mathrm{N} 2-\mathrm{CS} 8+\mathrm{H}_{2} \rightarrow \mathrm{N} 2-\mathrm{CS} 3+\mathrm{H}$

$\mathrm{N} 2-\mathrm{CS} 15 \rightarrow \mathrm{N} 2-\mathrm{CS} 8+\mathrm{C}_{2} \mathrm{H}_{2}$

$\mathrm{N} 2-\mathrm{CS} 22+\mathrm{H} \rightarrow \mathrm{N} 2-\mathrm{CS} 15$

$\mathrm{N} 2-\mathrm{CS} 9+\mathrm{H}_{2} \rightarrow \mathrm{N} 2-\mathrm{CS} 3+\mathrm{H}$

$\mathrm{N} 2-\mathrm{CS} 16 \rightarrow \mathrm{N} 2-\mathrm{CS} 9+\mathrm{C}_{2} \mathrm{H}_{2}$

$\mathrm{N} 2-\mathrm{CS} 23+\mathrm{H} \rightarrow \mathrm{N} 2-\mathrm{CS} 16$

$\mathrm{N} 2-\mathrm{CS} 33 \rightarrow \mathrm{N} 2-\mathrm{CS} 16$

$\mathrm{N} 2-\mathrm{CS} 23+\mathrm{H} \rightarrow \mathrm{N} 2-\mathrm{CS} 33$

$\mathrm{N} 2-\mathrm{CS} 34 \rightarrow \mathrm{N} 2-\mathrm{CS} 33$

$\mathrm{N} 2-\mathrm{CS} 35+\mathrm{H} \rightarrow \mathrm{N} 2-\mathrm{CS} 34$

$\mathrm{N} 2-\mathrm{CS} 10+\mathrm{H}_{2} \rightarrow \mathrm{N} 2-\mathrm{CS} 3+\mathrm{H}$

$\mathrm{N} 2-\mathrm{CS} 17 \rightarrow \mathrm{N} 2-\mathrm{CS} 10+\mathrm{C}_{2} \mathrm{H}_{2}$

$\mathrm{N} 2-\mathrm{CS} 36 \rightarrow \mathrm{N} 2-\mathrm{CS} 17$

$\mathrm{N} 2-\mathrm{CS} 35+\mathrm{H} \rightarrow \mathrm{N} 2-\mathrm{CS} 36$

$\mathrm{N} 2-\mathrm{CS} 24+\mathrm{H} \rightarrow \mathrm{N} 2-\mathrm{CS} 17$

$\mathrm{N} 2-\mathrm{CS} 43 \rightarrow \mathrm{N} 2-\mathrm{CS} 17$

$\mathrm{N} 2-\mathrm{CS} 24+\mathrm{H} \rightarrow \mathrm{N} 2-\mathrm{CS} 43$

$\mathrm{N} 2-\mathrm{CS} 44 \rightarrow \mathrm{N} 2-\mathrm{CS} 43$

$\mathrm{N} 2-\mathrm{CS} 4+\mathrm{H}_{2} \rightarrow \mathrm{N} 2-\mathrm{CS} 3+\mathrm{H}$

$\mathrm{N} 2-\mathrm{CS} 11 \rightarrow \mathrm{N} 2-\mathrm{CS} 4+\mathrm{C}_{2} \mathrm{H}_{2}$

$\mathrm{N} 2-\mathrm{CS} 25 \rightarrow \mathrm{N} 2-\mathrm{CS} 11$

$\mathrm{N} 2-\mathrm{CS} 26 \rightarrow \mathrm{N} 2-\mathrm{CS} 25$

$\mathrm{N} 2-\mathrm{CS} 18+\mathrm{H} \rightarrow \mathrm{N} 2-\mathrm{CS} 11$

$\mathrm{N} 2-\mathrm{CS} 18+\mathrm{H} \rightarrow \mathrm{N} 2-\mathrm{CS} 25$

$\mathrm{N} 2-\mathrm{CS} 44+\mathrm{H} \rightarrow \mathrm{A}_{3}{ }^{\mathrm{a}}$

Phenanthrene $\left(\mathrm{A}_{3}\right) \rightarrow$ Pyrene $\left(\mathrm{A}_{4}\right)$

$\mathrm{A}_{3}+\mathrm{H} \rightarrow \mathrm{P} 1-\mathrm{CS} 1+\mathrm{H}_{2}$

$\mathrm{P}-\mathrm{CS} 1+\mathrm{C}_{2} \mathrm{H}_{2} \rightarrow \mathrm{P} 1-\mathrm{CS} 2$

$\mathrm{P} 1-\mathrm{CS} 2 \rightarrow \mathrm{P} 1-\mathrm{CS} 4$

$\mathrm{P} 1-\mathrm{CS} 4 \rightarrow \mathrm{P} 1-\mathrm{CS} 5$

$\mathrm{P} 1-\mathrm{CS} 5 \rightarrow \mathrm{A}_{4}+\mathrm{H}$

$\mathrm{P} 1-\mathrm{CS} 2 \rightarrow \mathrm{P} 1-\mathrm{CS} 3+\mathrm{H}$

$\mathrm{P} 1-\mathrm{CS} 4 \rightarrow \mathrm{P} 1-\mathrm{CS} 3+\mathrm{H}$

$\mathrm{A}_{3}+\mathrm{H} \rightarrow \mathrm{P} 2-\mathrm{CS} 1+\mathrm{H}_{2}$

$\mathrm{P} 2-\mathrm{CS} 1+\mathrm{C}_{2} \mathrm{H}_{2} \rightarrow \mathrm{P} 2-\mathrm{CS} 2$

$\mathrm{P} 2-\mathrm{CS} 2 \rightarrow \mathrm{P} 2-\mathrm{CS} 3+\mathrm{H}$

$\mathrm{A}_{3}+\mathrm{H} \rightarrow \mathrm{P} 3-\mathrm{CS} 1+\mathrm{H}_{2}$

$\mathrm{P} 3-\mathrm{CS} 1+\mathrm{C}_{2} \mathrm{H}_{2} \rightarrow \mathrm{P} 3-\mathrm{CS} 2$

$\mathrm{P} 3-\mathrm{CS} 2 \rightarrow \mathrm{P} 3-\mathrm{CS} 3+\mathrm{H}$
$7.33 \times 10^{7}$
1.9090
16.66
$\mathrm{P} 1-\mathrm{CS} 1+\mathrm{H}_{2} \rightarrow \mathrm{A}_{3}+\mathrm{H}$
2.5340
6.69
$\mathrm{P} 1-\mathrm{CS} 2 \rightarrow \mathrm{P} 1-\mathrm{CS} 1+\mathrm{C}_{2} \mathrm{H}_{2}$
$1.61 \times 10^{12}$
0.1658
$4.10 \times 10^{11}$
$1.04 \times 10^{11}$
0.1168
0.7490
3.25
$\mathrm{P} 1-\mathrm{CS} 4 \rightarrow \mathrm{P} 1-\mathrm{CS} 2$
2.52
$\mathrm{P} 1-\mathrm{CS} 5 \rightarrow \mathrm{P} 1-\mathrm{CS} 4$
$5.82 \times 10^{11}$
0.8635
$5.06 \times 10^{11}$
0.8153
$1.27 \times 10^{8}$
1.9000
18.65
$\mathrm{A}_{4}+\mathrm{H} \rightarrow \mathrm{P} 1-\mathrm{CS} 5$
38.04
35.32
$\mathrm{P} 1-\mathrm{CS} 3+\mathrm{H} \rightarrow \mathrm{P} 1-\mathrm{CS} 2$
$3.60 \times 10^{4}$
$5.41 \times 10^{12}$
2.5970
16.41
$\mathrm{P} 1-\mathrm{CS} 3+\mathrm{H} \rightarrow \mathrm{P} 1-\mathrm{CS} 4$
0.7886
3.80
$1.55 \times 10^{8}$
1.8830
40.22
$\mathrm{P} 2-\mathrm{CS} 1+\mathrm{H}_{2} \rightarrow \mathrm{A}_{3}+\mathrm{H}$
$\mathrm{P} 2-\mathrm{CS} 2 \rightarrow \mathrm{P} 2-\mathrm{CS} 1+\mathrm{C}_{2} \mathrm{H}_{2}$
$\mathrm{P} 2-\mathrm{CS} 3+\mathrm{H} \rightarrow \mathrm{P} 2-\mathrm{CS} 2$
$5.58 \times 10^{4}$
$3.03 \times 10^{12}$
16.65
$\mathrm{P} 3-\mathrm{CS} 1+\mathrm{H}_{2} \rightarrow \mathrm{A}_{3}+\mathrm{H}$
2.5890
3.75
$\mathrm{P} 3-\mathrm{CS} 2 \rightarrow \mathrm{P} 3-\mathrm{CS} 1+\mathrm{C}_{2} \mathrm{H}_{2}$
$\mathrm{P} 3-\mathrm{CS} 3+\mathrm{H} \rightarrow \mathrm{P} 3-\mathrm{CS} 2$

$2.13 \times 10^{12}$

$5.23 \times 10^{9}$

0.3739

32.3

$5.23 \times 10^{9}$

$1.21 \times 10^{13}$

1.2734

1.2734

0.6206

$7.42 \times 10^{6}$

$6.44 \times 10^{6}$

$1.12 \times 10^{13}$

1.9073

1.9192

0.6524

$4.44 \times 10^{9}$

1.2671

1.2672

$3.12 \times 10^{9}$

1.2284

$7.94 \times 10^{6}$

$6.88 \times 10^{13}$

1.9069

0.5147

$4.66 \times 10^{9}$

$5.10 \times 10^{6}$

$3.91 \times 10^{13}$

$3.89 \times 10^{9}$

$6.84 \times 10^{6}$

$9.25 \times 10^{12}$

$7.53 \times 10^{9}$

$1.37 \times 10^{12}$

$8.13 \times 10^{9}$

$9.31 \times 10^{11}$

$3.58 \times 10^{9}$

$5.94 \times 10^{6}$

$9.50 \times 10^{12}$

$3.25 \times 10^{-6}$

$2.91 \times 10^{9}$

$6.89 \times 10^{9}$

$1.44 \times 10^{12}$

$6.89 \times 10^{9}$

$8.38 \times 10^{11}$

$8.10 \times 10^{6}$

$2.81 \times 10^{13}$

$4.97 \times 10^{12}$

$1.38 \times 10^{11}$

$5.00 \times 10^{9}$

$6.21 \times 10^{9}$

$1.00 \times 10^{14}$

1.2798

1.9619

0.4765

1.3021

1.9134

0.6990

1.2305

0.1278

1.2102 


\begin{tabular}{llllllll}
$\mathrm{A}_{3}+\mathrm{H} \rightarrow \mathrm{P} 4-\mathrm{CS} 1+\mathrm{H}_{2}$ & $1.26 \times 10^{8}$ & 1.8860 & 16.73 & $\mathrm{P} 4-\mathrm{CS} 1+\mathrm{H}_{2} \rightarrow \mathrm{A}_{3}+\mathrm{H}$ & $1.11 \times 10^{4}$ & 2.6560 & 7.48 \\
$\mathrm{P} 4-\mathrm{CS} 1+\mathrm{C}_{2} \mathrm{H}_{2} \rightarrow \mathrm{P} 4-\mathrm{CS} 2$ & $2.10 \times 10^{4}$ & 2.5860 & 4.06 & $\mathrm{P} 4-\mathrm{CS} 2 \rightarrow \mathrm{P} 4-\mathrm{CS} 1+\mathrm{C}_{2} \mathrm{H}_{2}$ & $1.56 \times 10^{14}$ & 0.3543 & 41.06 \\
$\mathrm{P} 4-\mathrm{CS} 2 \rightarrow \mathrm{P} 4-\mathrm{CS} 3+\mathrm{H}$ & $3.71 \times 10^{11}$ & 0.8492 & 37.58 & $\mathrm{P} 4-\mathrm{CS} 3+\mathrm{H} \rightarrow \mathrm{P} 4-\mathrm{CS} 2$ & $3.16 \times 10^{8}$ & 1.5820 & 3.89 \\
$\mathrm{P} 4-\mathrm{CS} 2 \rightarrow \mathrm{P} 4-\mathrm{CS} 4$ & $1.80 \times 10^{12}$ & 0.0887 & 1.93 & $\mathrm{P} 4-\mathrm{CS} 4 \rightarrow \mathrm{P} 4-\mathrm{CS} 2$ & $2.66 \times 10^{12}$ & 0.0462 & 3.40 \\
$\mathrm{P} 4-\mathrm{CS} 4 \rightarrow \mathrm{P} 4-\mathrm{CS} 3+\mathrm{H}$ & $6.43 \times 10^{11}$ & 0.8150 & 39.18 & $\mathrm{P} 4-\mathrm{CS} 3+\mathrm{H} \rightarrow \mathrm{P} 4-\mathrm{CS} 4$ & $4.66 \times 10^{8}$ & 1.5610 & 4.05 \\
$\mathrm{P} 4-\mathrm{CS} 4 \rightarrow \mathrm{P} 4-\mathrm{CS} 5$ & $3.57 \times 10^{11}$ & 0.1589 & 14.29 & $\mathrm{P} 4-\mathrm{CS} 5 \rightarrow \mathrm{P} 4-\mathrm{CS} 4$ & $8.66 \times 10^{12}$ & 0.2254 & 33.90 \\
$\mathrm{P} 4-\mathrm{CS} 5 \rightarrow \mathrm{P} 4-\mathrm{CS} 6+\mathrm{H}$ & $2.44 \times 10^{11}$ & 0.7518 & 28.22 & $\mathrm{P} 4-\mathrm{CS} 6+\mathrm{H} \rightarrow \mathrm{P} 4-\mathrm{CS} 5$ & $1.28 \times 10^{8}$ & 1.5930 & 3.40 \\
$\mathrm{~A}_{3}+\mathrm{H} \rightarrow \mathrm{P} 5-\mathrm{CS} 1+\mathrm{H}_{2}$ & $1.43 \times 10^{8}$ & 1.8750 & 16.67 & $\mathrm{P} 5-\mathrm{CS} 1+\mathrm{H}_{2} \rightarrow \mathrm{A}_{3}+\mathrm{H}$ & $1.11 \times 10^{4}$ & 2.6560 & 7.48 \\
$\mathrm{P} 5-\mathrm{CS} 1+\mathrm{C}_{2} \mathrm{H}_{2} \rightarrow \mathrm{P} 5-\mathrm{CS} 2$ & $2.00 \times 10^{4}$ & 2.6060 & 3.98 & $\mathrm{P} 5-\mathrm{CS} 2 \rightarrow \mathrm{P} 5-\mathrm{CS} 1+\mathrm{C}_{2} \mathrm{H}_{2}$ & $2.47 \times 10^{14}$ & 0.3188 & 41.20 \\
$\mathrm{P} 5-\mathrm{CS} 2 \rightarrow \mathrm{P} 5-\mathrm{CS} 3+\mathrm{H}$ & $3.79 \times 10^{11}$ & 0.8605 & 37.76 & $\mathrm{P} 5-\mathrm{CS} 3+\mathrm{H} \rightarrow \mathrm{P} 5-\mathrm{CS} 2$ & $3.06 \times 10^{8}$ & 1.5870 & 3.84 \\
$\mathrm{P} 5-\mathrm{CS} 2 \rightarrow \mathrm{P} 5-\mathrm{CS} 4$ & $2.94 \times 10^{12}$ & 0.0421 & 2.20 & $\mathrm{P} 5-\mathrm{CS} 4 \rightarrow \mathrm{P} 5-\mathrm{CS} 2$ & $3.93 \times 10^{12}$ & 0.0238 & 3.86 \\
$\mathrm{P} 5-\mathrm{CS} 4 \rightarrow \mathrm{P} 5-\mathrm{CS} 3+\mathrm{H}$ & $7.86 \times 10^{11}$ & 0.8104 & 39.56 & $\mathrm{P} 5-\mathrm{CS} 3+\mathrm{H} \rightarrow \mathrm{P} 5-\mathrm{CS} 4$ & $4.85 \times 10^{8}$ & 1.5530 & 3.99 \\
$\mathrm{P} 5-\mathrm{CS} 4 \rightarrow \mathrm{P} 5-\mathrm{CS} 5$ & $3.75 \times 10^{11}$ & 0.1586 & 15.38 & $\mathrm{P} 5-\mathrm{CS} 5 \rightarrow \mathrm{P} 5-\mathrm{CS} 4$ & $1.02 \times 10^{13}$ & 0.1896 & 32.86 \\
$\mathrm{P} 5-\mathrm{CS} 5 \rightarrow \mathrm{P} 5-\mathrm{CS} 6+\mathrm{H}$ & $2.56 \times 10^{11}$ & 0.7368 & 26.68 & $\mathrm{P} 5-\mathrm{CS} 6+\mathrm{H} \rightarrow \mathrm{P} 5-\mathrm{CS} 5$ & $1.22 \times 10^{8}$ & 1.5950 & 3.64 \\
\hline
\end{tabular}

${ }^{a}$ The rate coefficients are assumed to be equal as that of $\mathrm{B}-\mathrm{CS} 6+\mathrm{H} \rightarrow \mathrm{A}_{2}[26]$.

\subsection{The yield of products in HACA-based mass growth process}

Using the above PES and kinetic results, we investigated the yield distribution of various products within the HACA-based mass growth process. Here, the formation of various products are evaluated using a closed homogeneous zero-dimensional reactor for $\mathrm{A}_{1}-\mathrm{A}_{2}, \mathrm{~A}_{2}-\mathrm{A}_{2} \mathrm{R}_{5}-\mathrm{A}_{3}$, and $\mathrm{A}_{3}-\mathrm{A}_{4}$ reaction systems respectively, using Chemkin Pro software. The species considered in the 0-D reactor include $A_{1}\left(A_{2}\right.$ or $\left.A_{3}\right), C_{2} H_{2}, H_{2}, H$ and $N_{2}$ in the $A_{1}-A_{2}\left(A_{2}-A_{2} R_{5}-A_{3}\right.$ or $\left.A_{3}-A_{4}\right)$ reaction system. The mole fraction of $A_{1}, A_{2}, A_{3}, C_{2} H_{2}, H$, and $H_{2}$ are fixed at $5 \times 10^{-4}, 4 \times 10^{-5}, 1 \times 10^{-5}, 4 \times 10^{-2}, 1 \times 10^{-4}, 0.1$, in accordance with experimental results [54, 64]. The mole fraction of $\mathrm{N}_{2}$ is set to $0.8594,0.85986$, and 0.85989 in $\mathrm{A}_{1}-\mathrm{A}_{2}, \mathrm{~A}_{2}-\mathrm{A}_{3}$, and $\mathrm{A}_{3}-\mathrm{A}_{4}$ reaction systems respectively. The temperature is set to $1400 \mathrm{~K}$, which is the peak temperature of the measured temperature profile [54].

The mole fractions of various products in $\mathrm{A}_{1}-\mathrm{A}_{2}$ reaction system are shown in Fig.7 (a). The mole fraction of B$\mathrm{CS} 14$ (phenylacetylene, $\mathrm{A}_{1} \mathrm{C}_{2} \mathrm{H}$ ) is the highest, which is in agreement with the experimental results that $\mathrm{A}_{1} \mathrm{C}_{2} \mathrm{H}$ is the dominant product in the reaction of phenyl radical with $\mathrm{C}_{2} \mathrm{H}_{2}$ [65]. The concentration rank of secondary $\mathrm{C}_{2} \mathrm{H}_{2}$ addition products is in the following order: B-CS8 $>\mathrm{A}_{2}>\mathrm{B}-\mathrm{CS} 10>\mathrm{B}-\mathrm{CS} 11$. It matches with the above PES and kinetic analysis that $\mathrm{C}_{2} \mathrm{H}_{2}$ is more likely to attach to the active $\mathrm{C}$ atom far from the $\mathrm{C}_{2} \mathrm{H}$ chain. In the reaction system of $A_{2}-A_{2} R_{5}-A_{3}$, the $A_{2} R_{5}$ is the dominant reaction product, and its mole fraction is higher than that of $\mathrm{A}_{3}$ by at least 27.8 times as shown in Fig.7 (b). These results are in good agreement with the theoretical results by Kislov et al. [58], where $A_{3}$ is the minor product in the $A_{2}-C_{2} H_{2}$ reaction system. In the $A_{3}-A_{4}$ reaction system, the yield of products is mainly determined by the type of surface site as it makes reaction coefficients of $\mathrm{H}$ abstraction and $\mathrm{C}_{2} \mathrm{H}_{2}$ addition reactions different, as well as the thermal stability of product. In this study, the thermal stability rank of products is in the following order: PAHs with one or two $\mathrm{C}_{2} \mathrm{H}$ chains (eg: P2-CS3 and P3-CS3) < PAHs with 5-membered rings (eg: P5-CS6) < PAHs containing only benzene rings (eg: $\mathrm{A}_{4}$ ) as shown 
in Fig.5. The formation of P2-CS3 and P3-CS3 is kinetically supported by the $\mathrm{H}$ abstraction and $\mathrm{C}_{2} \mathrm{H}_{2}$ addition reactions, as shown in Fig.6 (b) and (d). However, their concentration peaks around $0.5 \mathrm{~ms}$, then decrease rapidly as shown in Fig.7 (c). It should be resulted from the low thermal stability of P2-CS3 and P3-CS3 molecules, which make the reaction highly reversible at flame temperature. Fig.7 (c) shows that the P5-CS6 with 5-membered rings with moderate thermal stability is the dominant product in this reaction system, and its mole fraction is higher than that of $\mathrm{A}_{4}$ by 45.6 times. The $\mathrm{A}_{4}$ formation is greatly limited by the rate coefficients of $\mathrm{H}$ abstraction and $\mathrm{C}_{2} \mathrm{H}_{2}$ addition reactions. Based on the yield distribution of products in $\mathrm{A}_{2}-\mathrm{A}_{2} \mathrm{R}_{5}-\mathrm{A}_{3}$ and $\mathrm{A}_{3}-\mathrm{A}_{4}$ reaction systems, we can deduce that the PAHs with 5-membered ring should be the dominant reaction products in HACAbased mass growth processes instead of PAHs containing only benzene rings, especially in large PAHs or soot surface growth processes. We also noted that the mole fraction of all intermediates are always lower than $1 \times 10^{-}$ ${ }^{10}$, which is lower than the main reaction products by at least three orders of magnitudes. This means the steadystate approximation, where the reaction intermediate consumed as quickly as it is generated and the concentration remains the same in a duration of the reaction, can be applied for HACA pathways to reduce the reaction number in mechanism simplification.

To discuss the importance of the Frenklach route where the active $\mathrm{C}$ atom generates through the intramolecular $\mathrm{H}$ transfer to the $\mathrm{C}_{2} \mathrm{H}_{2}$ chain (like routes N1-CS33 $\rightarrow \mathrm{A}_{3}+\mathrm{H}$ and N2-CS37 $\rightarrow \mathrm{A}_{3}+\mathrm{H}$ in Fig.2), the sensitivity of $\mathrm{A}_{3}$ formation pathway is carried out. Considering the site effect, there are three $\mathrm{A}_{3}$ formation pathways including Frenklach, N1-CS5 $\rightarrow \mathrm{A}_{3}$ and $\mathrm{N} 2-\mathrm{CS} 3 \rightarrow \mathrm{A}_{3}$ routes. The mole fraction of $\mathrm{A}_{3}$ is calculated on the condition that each route is removed from $\mathrm{A}_{3}$ formation network individually. The importance of each route can be evaluated by comparing the $\mathrm{A}_{3}$ concentration calculated with and without the corresponding route. As shown in Fig.7 (d), only $4.96 \%$ of $A_{3}$ is formed from the Frenklach route, and that most $A_{3}(90.5 \%)$ is formed from the HACA route: $\mathrm{A}_{2}+\mathrm{C}_{2} \mathrm{H}_{2} \rightarrow \mathrm{N} 2-\mathrm{CS} 3\left(\mathrm{C}_{2} \mathrm{H}_{2}\right) \rightarrow \mathrm{A}_{3}+\mathrm{H}$

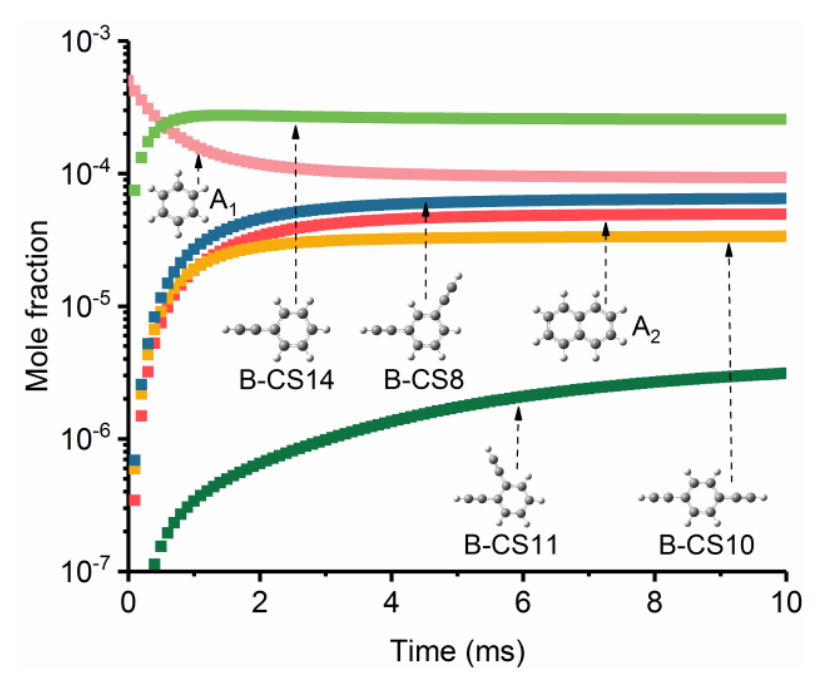

(a)

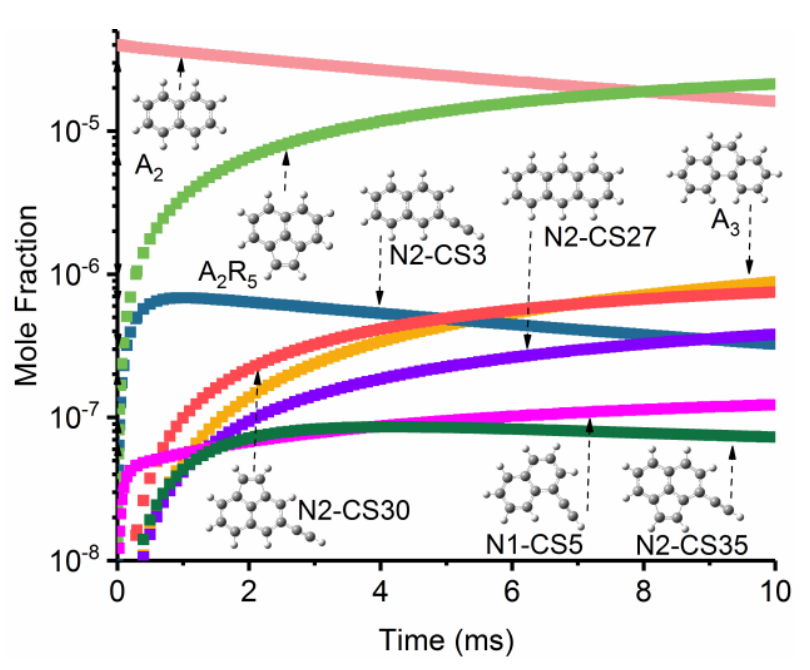

(b) 


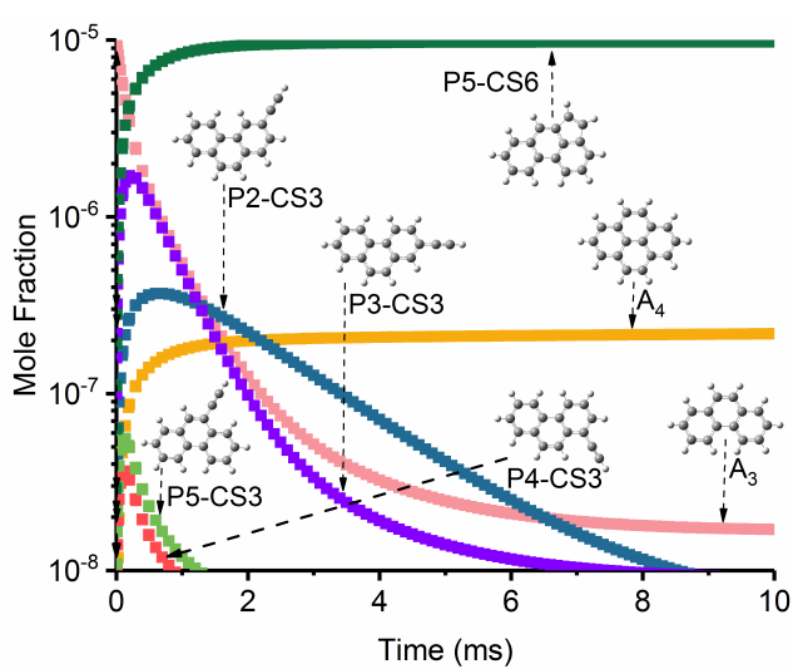

(c)

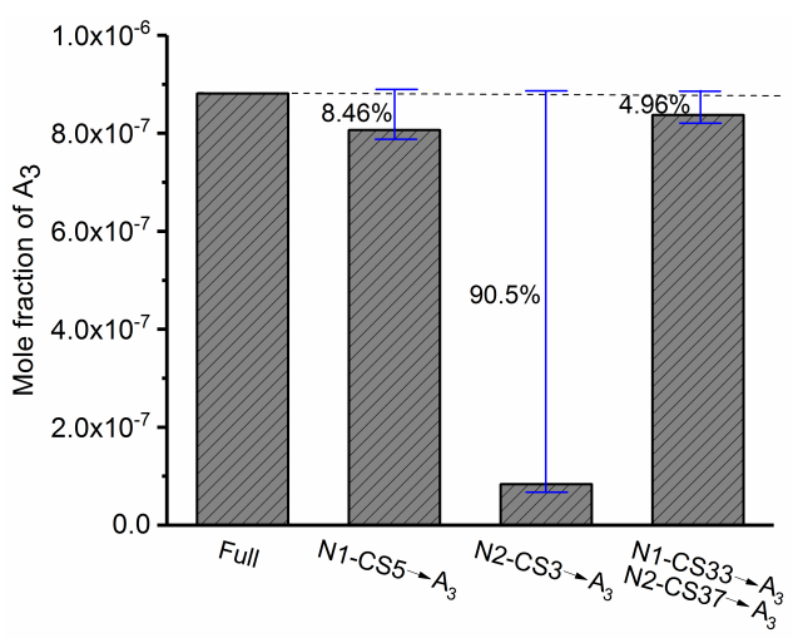

(d)

Fig.7. The yield of products in $A_{1}-A_{2}$ system (a), $A_{2}-A_{2} R_{5}-A_{3}$ system (b), $A_{3}-A_{4}$ system (c), and $A_{3}$ formation pathway analysis (d).

\subsection{Connections to PAHs experiment}

Generally, comparison between experimental observation and theoretical results updates our understanding of PAH formation. To this end, experimental results that detect PAHs using LIF [66-68], TOFMS [69] and GC-MS technique [54] are selected for discussions. The first two qualitatively describes the formation of PAHs, and the last one quantitatively describes the concentrations of PAHs up to pyrene. In LIF experiment, the detected fluorescence wavelength of PAHs ranges from $300 \mathrm{~nm}$ to $700 \mathrm{~nm}$ in premixed flames [66-68]. At a given flame height, the LIF signal intensity along fluorescence wavelength increases first, then decreases after reaching a peak value around $500 \mathrm{~nm}$. Liu et al. [70] suggests that the signal in the UV region can be regarded as the fluorescence being emitted by the PAHs with two to three rings, and the fluorescence signals with the wavelength in the visible region are likely emitted by the PAHs with 5-membered rings. The above yield analysis indicates that concentrations of PAHs with 5-membered rings including $\mathrm{A}_{2} \mathrm{R}_{5}, \mathrm{~N} 2-\mathrm{CS} 30$ and P5-CS6 are expected to be high in premixed sooting flame. The existence of abundant PAHs with 5-membered rings contributes to explaining that the PAH-LIF profile peaks in the visible region.

Shukla et al. [69] proposed that hydrogen abstraction and vinyl radical $\left(\mathrm{C}_{2} \mathrm{H}_{3}\right)$ addition (HAVA) pathway is more promising compared with HACA pathway in $\mathrm{C}_{2} \mathrm{H}_{4}$ flame, as a remarkable sequence of mass peak at intervals of mass number 26 instead of 24 was observed in the case of $\mathrm{C}_{2} \mathrm{H}_{4}$ pyrolysis products using TOFMS technique. However, the mole fraction of $\mathrm{C}_{2} \mathrm{H}_{3}$ is lower than that of $\mathrm{C}_{2} \mathrm{H}_{2}$ by at least four orders of magnitude in $\mathrm{C}_{2} \mathrm{H}_{4}$ sooting flame. The simulated peak mole fraction of $\mathrm{C}_{2} \mathrm{H}_{3}$ is $2 \times 10^{-6}$, and that of $\mathrm{C}_{2} \mathrm{H}_{2}$ is $4 \times 10^{-2}$ in premixed $\mathrm{C}_{2} \mathrm{H}_{4} \mathrm{flame}$ with equivalence ratio of 3.06 using ABF mechanism [26]. This means that the contribution of PAHs formation 
from HAVA pathway is expected to be small due to the low concentration of $\mathrm{C}_{2} \mathrm{H}_{3}$. In this study, the formation of PAH isomers considering site effects is more attractive to explain the observed mass spectra results. The formation of 1,3-Diethynylbenzene (B-CS8), 1,4-Diethynylbenzene (B-CS10), N2-CS30 and N2-CS35 account for mass peaks at 126 and 176, which are not considered in any PAH mechanisms. In this way, the observed sequence of mass peaks at intervals of mass number 26 may result from the reaction pathways of $\mathrm{C}_{8} \mathrm{H}_{6} \rightarrow \mathrm{C}_{10} \mathrm{H}_{8}$, $\mathrm{C}_{10} \mathrm{H}_{6} \rightarrow \mathrm{C}_{12} \mathrm{H}_{8} \rightarrow \mathrm{C}_{14} \mathrm{H}_{10}$ and $\mathrm{C}_{14} \mathrm{H}_{8} \rightarrow \mathrm{C}_{16} \mathrm{H}_{10}$, and the corresponding attribution of the mass peaks are shown in Fig.8. It is notable that the mass peak at $178\left(\mathrm{C}_{14} \mathrm{H}_{8}\right)$ is not observed in $\mathrm{C}_{2} \mathrm{H}_{2}$ pyrolysis, but observed with a weak signal intensity in $\mathrm{C}_{2} \mathrm{H}_{4}$ pyrolysis. It indicates that the formation of $\mathrm{A}_{3}\left(\mathrm{C}_{14} \mathrm{H}_{8}\right)$ within HACA frame is greatly limited, which confirms the aforementioned conclusion. The formation of larger PAHs (e.g., $\left.A_{2} \rightarrow A_{3}\right)$ via the reaction of PAH radical and vinylacetylene $\left(\mathrm{C}_{4} \mathrm{H}_{4}\right)$ is also possible, as supported by experimental and theoretical evidence for the reaction of phenyl radical and $\mathrm{C}_{4} \mathrm{H}_{4}$ generating $\mathrm{A}_{2}$ (like $\mathrm{A}_{1} \rightarrow \mathrm{A}_{2}$ ) under different conditions [7173]. In order to complement the HACA framework, future work should pay more attention to $\mathrm{PAH}$ radical $+\mathrm{C}_{4} \mathrm{H}_{4}$ reactions.

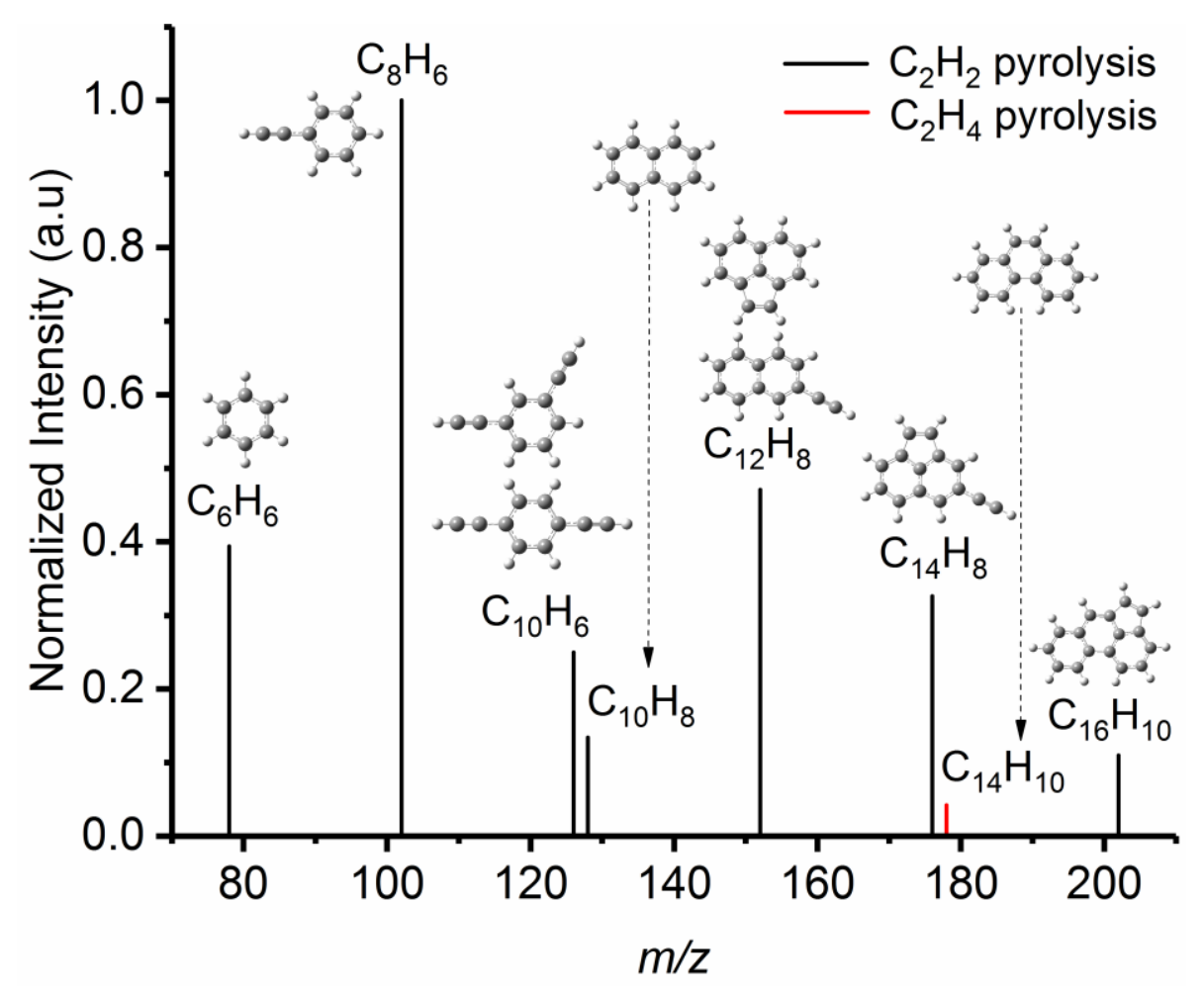

Fig.8. The mass spectra of acetylene and ethylene pyrolysis products observed at $1485 \mathrm{~K}$ [69].

To evaluate the site effect on the concentration of PAHs formed in the HACA route, PAH formation in premixed $\mathrm{C}_{2} \mathrm{H}_{4} / \mathrm{O}_{2} / \mathrm{N}_{2}$ flames [54] is simulated using the premixed flame model in Chemkin software. The USC II mechanism where benzene is the termination species is considered as the base-mechanism, and the investigated 
186 elementary reactions listed in Table 2 are embedded into USC II mechanism. The new mechanism is named as "PAHs mechanism with site effects" in this study. If only the formation of $A_{2}, A_{2} R_{5}, A_{3}$ and $A_{4}$ is considered in the reaction networks, then the mechanism is labeled as "PAHs mechanism without site effect". It is notable that this study only focus on the HACA route, so other pathway beyond HACA route is not considered. In this way, the relative contribution to PAHs formation from HACA route can be evaluated by comparing the experimentally detected PAHs concentration and predicted PAHs concentration using the PAHs mechanism here. Flame conditions including the temperature profile, equivalence ratio and velocity of inlet-gas are kept the same as experimental data [54]. As illustrated in Fig.9 (a)-(b), the mole fractions of $\mathrm{A}_{1}$ and $\mathrm{A}_{1} \mathrm{C}_{2} \mathrm{H}$ are in accordance with the experimental data, and the deviation is generally within a factor of 3 . In addition, the site effect on the mole fractions of $\mathrm{A}_{1}$ and $\mathrm{A}_{1} \mathrm{C}_{2} \mathrm{H}$ is ignorable. The mole fraction of $\mathrm{A}_{2}$ predicted by the $\mathrm{PAH}$ mechanism with site effects more closely agrees with the experimental profile, compared with the model without site effect as presented in Fig.9 (c). The comparison results mean that the formation of aromatic species up to $\mathrm{A}_{2}$ can be accurately descripted by HACA route, at least for this flame case. The mole fraction of $\mathrm{A}_{2}$ is determined by the competition between the formation and consumption rate. The main precursors of $A_{2}$ formation are $A_{1} C_{2} H_{\text {and }}$ $\mathrm{C}_{2} \mathrm{H}_{2}$, and their concentration profiles are almost the same irrespective of the site effect. Therefore, it implies that the reduced consumption of $A_{2}$ in $A_{2} R_{5}$ and $A_{3}$ formation process should be the main reason for the better performance of the PAHs mechanism with site effect. Indeed, the mole fractions of larger PAHs including $\mathrm{A}_{2} \mathrm{R}_{5}$, $A_{3}$ and $A_{4}$ simulated with site effect are much lower than that without site effect, as shown in Fig.9 (d)-(f). In addition, the predicted mole fractions of $\mathrm{A}_{3}$ and $\mathrm{A}_{4}$ with or without site effect in HACA frame are lower than that of experimental results by at least two orders of magnitudes. It agrees well with the mass spectra experiments for HACA-based reactions, where the mass peak at $A_{3}$ is not observed [65] or observed at a very weak signal intensity [69]. Therefore, reaction pathways beyond the HACA pathway should be investigated for accurate prediction of $\mathrm{A}_{3}$ and $\mathrm{A}_{4}$.

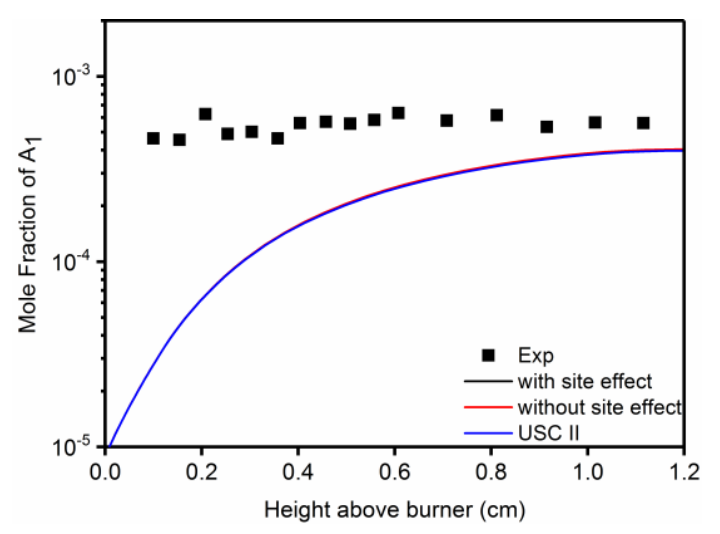

(a)

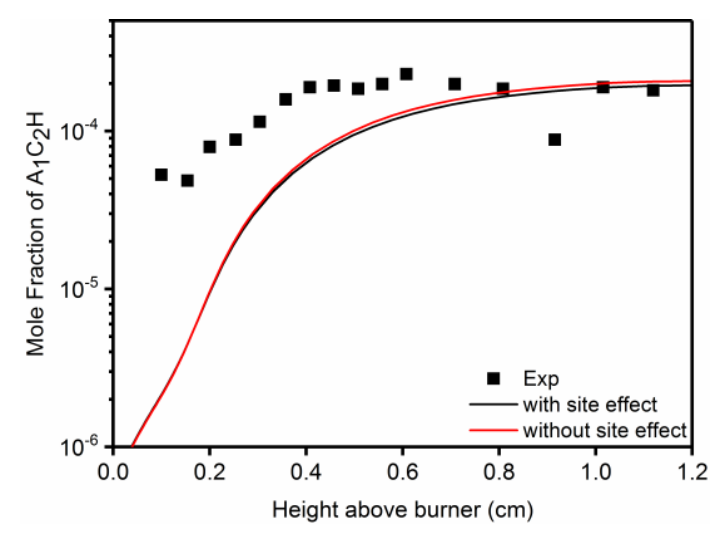

(b) 


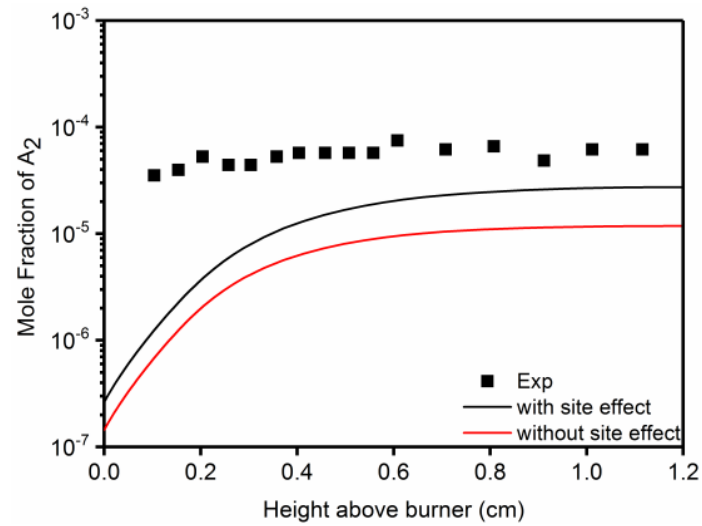

(c)

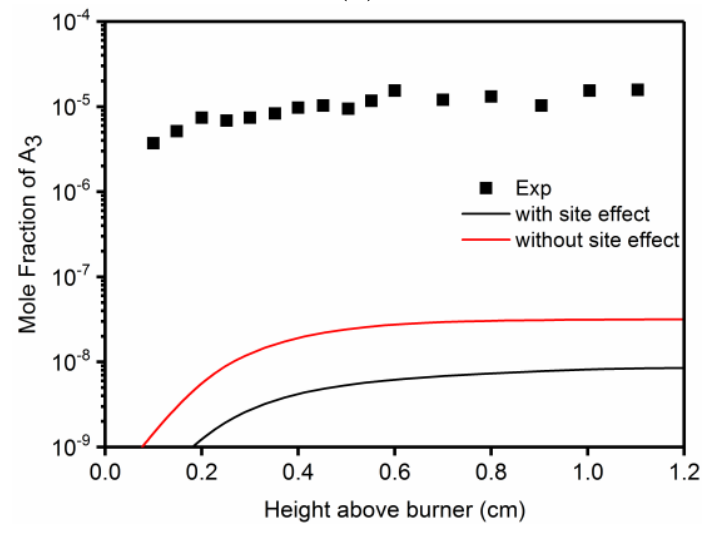

(e)

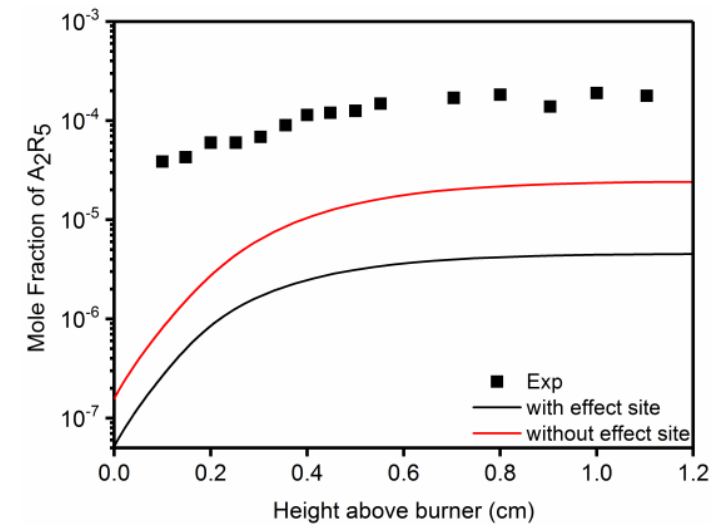

(d)

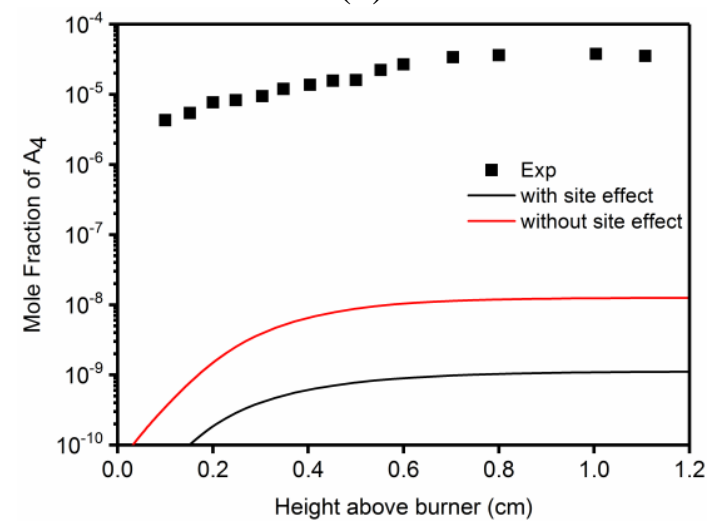

(f)

Fig. 9 Comparison between experimental and calculated mole fraction of benzene and various $\mathrm{PAHs}_{\text {in }} \mathrm{C}_{2} \mathrm{H}_{4}$ premixed flame [54]. (1 atm, $\left.\mathrm{C}_{2} \mathrm{H}_{4} / \mathrm{O}_{2} / \mathrm{N}_{2}=21.3 / 20.9 / 57.8\right)$.

\section{Conclusion}

The site effect on PAH growth from benzene to pyrene within the HACA framework was systematically investigated by applying both DFT B3LYP 6-311+G(d,p) and TST methods. Also, the yield distribution of various products in $\mathrm{A}_{1}-\mathrm{A}_{2}, \mathrm{~A}_{2}-\mathrm{A}_{2} \mathrm{R}_{5}-\mathrm{A}_{3}$, and $\mathrm{A}_{3}-\mathrm{A}_{4}$ reaction systems is calculated using a $0-\mathrm{D}$ reactor simulation. Additionally, the correlation of theoretical results with LIF, TOFMS and GC-MS experimental results was discussed. The following conclusions can be drawn from this study.

The potential energy surface and kinetic analysis indicate that the $\mathrm{H}$ abstraction and $\mathrm{C}_{2} \mathrm{H}_{2}$ addition reactions are greatly sensitive to the site position (ortho-, meta- and para-position) relative to the $\mathrm{C}_{2} \mathrm{H}$ chain and surface site type (zig-zag, free-edge and armchair). The $\mathrm{H}$ atoms located at the meta- and para positions are more likely to be abstracted from the PAHs. In addition, the active $\mathrm{C}$ atom on the free-edge of PAHs is the priority target of $\mathrm{C}_{2} \mathrm{H}_{2}$ molecule, compared with zig-zag and armchair surface site.

Considering the site effect, our results show that the di-substituted PAHs and PAHs with 5-membered ring can be formed in the HACA framework. The yield distribution results indicate that PAHs with 5-membered ring with 
moderate thermal stability are the dominant reaction product in HACA-based mass growth processes, especially for larger PAH reactions. Furthermore, the formation of multi-ring PAHs fully constituted of benzene rings is kinetically unsupported in the HACA framework.

The sensitivity analysis of $\mathrm{A}_{3}$ formation pathway indicates that the Frenklach route, wherein the active $\mathrm{C}$ atom is generated via the intramolecular $\mathrm{H}$ transfer to the $\mathrm{C}_{2} \mathrm{H}_{2}$ chain, can be ignored in PAHs mechanism for brevity.

The existence of abundant PAHs with 5-membered ring is indirectly confirmed by the dominant features of PAH-LIF signal profiles. The observed sequence of mass peak at intervals of mass number 26 in $\mathrm{C}_{2} \mathrm{H}_{2} / \mathrm{C}_{2} \mathrm{H}_{4}$ pyrolysis is reasonably explained by the theoretical results in this study. The comparison of the simulated PAH concentrations that consider site effects and detected PAH concentrations using GC-MS method reveals that the HACA pathway significantly underestimates the concentrations of phenanthrene and pyrene. The potential formation pathways for phenanthrene and pyrene should be explored in future.

\section{Reference}

[1] W.M. Baird, L.A. Hooven, B. Mahadevan, Carcinogenic polycyclic aromatic hydrocarbon-DNA adducts and mechanism of action, Environmen. mol. mutagen. 45 (2005) 106-114.

[2] B. Binková, R.J. Šrám, The genotoxic effect of carcinogenic PAHs, their artificial and environmental mixtures (EOM) on human diploid lung fibroblasts, Mutat. Res-Fund. Mol. M. 547 (2004) 109-121.

[3] S.H. Chung, A. Violi, Nucleation of fullerenes as a model for examining the formation of soot, J. Chem. Phys. 132 (2010) 174502.

[4] A. Violi, A. Kubota, T.N. Truong, W.J. Pitz, C.K. Westbrook, A.F. Sarofim, A fully integrated kinetic monte carlo/molecular dynamics approach for the simulation of soot precursor growth, P. Combust. Inst. 29 (2002) 2343-2349.

[5] S.B. Dworkin, Q. Zhang, M.J. Thomson, N.A. Slavinskaya, U. Riedel, Application of an enhanced PAH growth model to soot formation in a laminar coflow ethylene/air diffusion flame, Combust. Flame 158 (2011) 1682-1695.

[6] V. Chernov, M.J. Thomson, S.B. Dworkin, N.A. Slavinskaya, U. Riedel, Soot formation with C1 and C2 fuels using an improved chemical mechanism for PAH growth, Combust. Flame 161 (2014) 592-601.

[7] P. Selvaraj, P.G. Arias, B.J. Lee, H.G. Im, Y. Wang, Y. Gao, S. Park, S.M. Sarathy, T. Lu, S.H. Chung, A computational study of ethylene-air sooting flames: Effects of large polycyclic aromatic hydrocarbons, Combust. Flame 163 (2016) 427-436.

[8] C. Shao, B. Guan, B. Lin, H. Gu, C. Gu, Z. Li, H. Lin, Z. Huang, Effect of methane doping on nascent soot formation in ethylene-based laminar premixed flames, Fuel 186 (2016) 422-429.

[9] X. Pei, L.Y. Hou, Effect of dissolved oxygen concentration on coke deposition of kerosene, Fuel Process. Technol. 142 (2016) 86-91.

[10] Q. Tang, H. Liu, M. Li, C. Geng, M. Yao, Multiple optical diagnostics on effect of fuel stratification degree on reactivity controlled compression ignition, Fuel 202 (2017) 688-698.

[11] Q. Tang, H. Liu, M. Li, M. Yao, Z. Li, Study on ignition and flame development in gasoline partially premixed combustion using multiple optical diagnostics, Combust. Flame 177 (2017) 98-108. 
[12] S. Banerjee, D. Bhattacharyya, Electronic properties of nano-graphene sheets calculated using quantum chemical DFT, Comp. Mater. Sci. 44 (2008) 41-45.

[13] F. Liu, P. Ming, J. Li, Ab initio calculation of ideal strength and phonon instability of graphene under tension, Phys. Rev. B 76 (2007) 064120.

[14] S. Park, R.S. Ruoff, Chemical methods for the production of graphenes, Nat. nanotechnol. 4 (2009) 217.

[15] J.Y. Seok, H. Hirashita, R.S. Asano, Formation history of polycyclic aromatic hydrocarbons in galaxies, Mon. Not. R. Astron. Soc. 439 (2014) 2186-2196.

[16] L. Zhao, R.I. Kaiser, B. Xu, U. Ablikim, M. Ahmed, D. Joshi, G. Veber, F.R. Fischer, A.M. Mebel, Pyrene synthesis in circumstellar envelopes and its role in the formation of 2D nanostructures, Nat. Astron. 2 (2018) 413419.

[17] H. Wang, M. Frenklach, Calculations of Rate Coefficients for the Chemically Activated Reactions of Acetylene with Vinylic and Aromatic Radicals, J. Phys. Chem. 98 (1994) 11465-11489.

[18] M. Frenklach, Reaction mechanism of soot formation in flames, Phys. Chem. Chem. Phys. 4 (2002) 20282037.

[19] P. Liu, H. Lin, Y. Yang, C. Shao, B. Guan, Z. Huang, Investigating the Role of CH2 Radicals in the HACA Mechanism, J. Phys. Chem. A 119 (2015) 3261-3268.

[20] A. Raj, I.D.C. Prada, A.A. Amer, S.H. Chung, A reaction mechanism for gasoline surrogate fuels for large polycyclic aromatic hydrocarbons, Combust. Flame 159 (2012) 500-515.

[21] A. Raj, G.R. da Silva, S.H. Chung, Reaction mechanism for the free-edge oxidation of soot by O2, Combust. Flame 159 (2012) 3423-3436.

[22] K. Utsav, M. Beshir, A. Farooq, Simultaneous measurements of acetylene and soot during the pyrolysis of ethylene and benzene in a shock tube, P. Combust. Inst. 36 (2017) 833-840.

[23] P. Liu, Z. Li, W.L. Roberts, The growth of PAHs and soot in the post-flame region, P. Combust. Inst. doi:https://doi.org/10.1016/j.proci.2018.05.047(2018).

[24] P. Liu, H. Lin, Z. He, Y. Zhang, B. Guan, Z. Huang, The mechanism and kinetic analysis of C4H4 + C4H4 (but-1-ene-3-yne) reaction with features of H-transfer in combustion, Int. J. Hydrog. Energy 41 (2016) 3249-3258. [25] X. Pei, L. Hou, Z. Ren, Kinetic Modeling of Thermal Oxidation and Coking Deposition in Aviation Fuel, Energ. Fuel. 31 (2017) 1399-1405.

[26] J. Appel, H. Bockhorn, M. Frenklach, Kinetic modeling of soot formation with detailed chemistry and physics: laminar premixed flames of C2 hydrocarbons, Combust. Flame 121 (2000) 122-136.

[27] Y. Wang, A. Raj, S.H. Chung, A PAH growth mechanism and synergistic effect on PAH formation in counterflow diffusion flames, Combust. Flame 160 (2013) 1667-1676.

[28] H. Lin, P. Liu, Z. He, Y. Zhang, B. Guan, Z. Huang, Formation of the first aromatic ring through the selfrecombination of but-1-ene-3-yne with H-assistance in combustion, Int. J. Hydrog. Energy 41 (2016) 1373613746.

[29] Y. Wang, S. Park, S.M. Sarathy, S.H. Chung, A comparative study on the sooting tendencies of various 1alkene fuels in counterflow diffusion flames, Combust. Flame 192 (2018) 71-85.

[30] A. Raj, M.J. Al Rashidi, S.H. Chung, S.M. Sarathy, PAH growth initiated by propargyl addition: mechanism development and computational kinetics, J. Phys. Chem. A 118 (2014) 2865-2885.

[31] Y.Z. An, Y.Q. Pei, J. Qin, H. Zhao, X. Li, Kinetic modeling of polycyclic aromatic hydrocarbons formation process for gasoline surrogate fuels, Energ. Convers. Manage. 100 (2015) 249-261.

[32] Y.Z. An, X. Li, S.-p. Teng, K. Wang, Y.Q. Pei, J. Qin, H. Zhao, Development of a soot particle model with PAHs as precursors through simulations and experiments, Fuel 179 (2016) 246-257.

[33] Y.Z. An, Y.Q. Pei, J. Qin, H. Zhao, S.P. Teng, B. Li, X. Li, Development of a PAH (polycyclic aromatic hydrocarbon) formation model for gasoline surrogates and its application for GDI (gasoline direct injection) engine CFD (computational fluid dynamics) simulation, Energy 94 (2016) 367-379.

[34] Y.Z. An, M. Jaasim, R. Vallinayagam, S. Vedharaj, H.G. Im, B. Johansson, Numerical simulation of combustion and soot under partially premixed combustion of low-octane gasoline, Fuel 211 (2018) 420-431. 
[35] C. Eberle, P. Gerlinger, M. Aigner, A sectional PAH model with reversible PAH chemistry for CFD soot simulations, Combust. Flame 179 (2017) 63-73.

[36] C. Shao, H. Wang, N. Atef, Z. Wang, B. Chen, M. Almalki, Y. Zhang, C. Cao, J. Yang, S.M. Sarathy, Polycyclic aromatic hydrocarbons in pyrolysis of gasoline surrogates (n-heptane/iso-octane/toluene), P. Combust. Inst. doi:https://doi.org/10.1016/j.proci.2018.06.087(2018).

[37] S. Park, Y. Wang, S.H. Chung, S.M. Sarathy, Compositional effects on PAH and soot formation in counterflow diffusion flames of gasoline surrogate fuels, Combust. Flame 178 (2017) 46-60.

[38] X. Pei, L. Hou, W.L. Roberts, Experimental and Numerical Study on Oxidation Deposition Properties of Aviation Kerosene, Energ. Fuel. 32 (2018) 7444-7450.

[39] K.O. Johansson, J.Y.W. Lai, S.A. Skeen, D.M. Popolan-Vaida, K.R. Wilson, N. Hansen, A. Violi, H.A. Michelsen, Soot precursor formation and limitations of the stabilomer grid, P. Combust. Inst. 35 (2015) 18191826.

[40] F. Schulz, M. Commodo, K. Kaiser, G. De Falco, P. Minutolo, G. Meyer, A. D`Anna, L. Gross, Insights into incipient soot formation by atomic force microscopy, $\mathrm{P}$. Combust. Inst. doi:https://doi.org/10.1016/j.proci.2018.06.100(2018).

[41] D.S. Parker, R. Kaiser, B. Bandyopadhyay, O. Kostko, T.P. Troy, M. Ahmed, Unexpected Chemistry from the Reaction of Naphthyl and Acetylene at Combustion-Like Temperatures, Angew. Chem. Int. Edit. 127 (2015) 5511-5514.

[42] A. Semenikhin, A. Savchenkova, I. Chechet, S. Matveev, Z. Liu, M. Frenklach, A. Mebel, Rate constants for $\mathrm{H}$ abstraction from benzo (a) pyrene and chrysene: a theoretical study, Phys. Chem. Chem. Phys. 19 (2017) 25401-25413.

[43] P. Liu, H. Lin, Y. Yang, C. Shao, C. Gu, Z. Huang, New Insights into Thermal Decomposition of Polycyclic Aromatic Hydrocarbon Oxyradicals, J. Phys. Chem. A 118 (2014) 11337-11345.

[44] X. You, H. Wang, H.-B. Zhang, M.J. Pilling, Thermal decomposition of graphene oxyradicals under the influence of an embedded five-membered ring, Phys. Chem. Chem. Phys. 18 (2016) 12149-12162.

[45] A.D. Becke, Density-functional thermochemistry. III. The role of exact exchange, J. Chem. Phys. (1993) 5648-5652.

[46] D.E. Edwards, D.Y. Zubarev, W.A. Lester Jr, M. Frenklach, Pathways to soot oxidation: reaction of OH with phenanthrene radicals, J. Phys. Chem. A 118 (2014) 8606-8613.

[47] R.D. Johnson, NIST Computational Chemistry Comparison and Benchmark Database, National Institute of Standards and Technology: Gaithersburg, MD, (2005).

[48] E.K. Pokon, M.D. Liptak, S. Feldgus, G.C. Shields, Comparison of CBS-QB3, CBS-APNO, and G3 Predictions of Gas Phase Deprotonation Data, J. Phys. Chem. A 105 (2001) 10483-10487.

[49] K. Ishida, K. Morokuma, A. Komornicki, The intrinsic reaction coordinate. An abinitio calculation for $\mathrm{HNC} \rightarrow \mathrm{HCN}$ and $\mathrm{H}-+\mathrm{CH} 4 \rightarrow \mathrm{CH} 4+\mathrm{H}-$, J. Chem. Phys. 66 (1977) 2153-2156.

[50] M.J. Frisch, G.W. Trucks, H.B. Schlegel, G.E. Scuseria, M.A. Robb, J.R. Cheeseman, et al., Gaussian 09 revision D.01, Gaussian, Inc., Wallingford, CT, (2013).

[51] A.M. Mebel, Y. Georgievskii, A.W. Jasper, S.J. Klippenstein, Temperature- and pressure-dependent rate coefficients for the HACA pathways from benzene to naphthalene, P. Combust. Inst. 36 (2017) 919-926.

[52] T.N. Truong, Reaction class transition state theory: Hydrogen abstraction reactions by hydrogen atoms as test cases, J. Chem. Phys. 113 (2000) 4957-4964.

[53] H. Wang, M. Frenklach, Transport properties of polycyclic aromatic hydrocarbons for flame modeling, Combust. Flame 96 (1994) 163-170.

[54] M.J. Castaldi, N.M. Marinov, C.F. Melius, J. Huang, S.M. Senkan, W.J. Pit, C.K. Westbrook, Experimental and modeling investigation of aromatic and polycyclic aromatic hydrocarbon formation in a premixed ethylene flame, P. Combust. Inst. 26 (1996) 693-702.

[55] M. Frenklach, H. Wang, Detailed modeling of soot particle nucleation and growth, P. Combust. Inst. (1991) 1559-1566. 
[56] J. Bittner, J. Howard. Composition profiles and reaction mechanisms in a near-sooting premixed benzene/oxygen/argon flame. P. Combust. Inst. 18 (1981) 1105-1116.

[57] M. Frenklach, Z. Liu, R.I. Singh, G.R. Galimova, V.N. Azyazov, A.M. Mebel, Detailed, sterically-resolved modeling of soot oxidation: Role of $\mathrm{O}$ atoms, interplay with particle nanostructure, and emergence of inner particle burning, Combust. Flame 188 (2018) 284-306.

[58] V.V. Kislov, A.I. Sadovnikov, A.M. Mebel, Formation Mechanism of Polycyclic Aromatic Hydrocarbons beyond the Second Aromatic Ring, J. Phys. Chem. A 117 (2013) 4794-4816.

[59] B.R. Giri, T. Bentz, H. Hippler, M. Olzmann, Shock-tube study of the reactions of hydrogen atoms with benzene and phenyl radicals, Z. Phys. Chem. 223 (2009) 539-549.

[60] E. Heckmann, H. Hippler, J. Troe, High-temperature reactions and thermodynamic properties of phenyl radicals, P. Combust. Inst. 26 (1996) 543-550.

[61] A.G. Baboul, L.A. Curtiss, P.C. Redfern, K. Raghavachari, Gaussian-3 theory using density functional geometries and zero-point energies, J. Chem. Phys. 110 (1999) 7650-7657.

[62] L.A. Curtiss, K. Raghavachari, P.C. Redfern, A.G. Baboul, J.A. Pople, Gaussian-3 theory using coupled cluster energies, Chem. phys. lett. 314 (1999) 101-107.

[63] M. Frenklach, R.I. Singh, A.M. Mebel, On the low-temperature limit of HACA, Proceedings of the Combustion Institute, doi:https://doi.org/10.1016/j.proci.2018.05.068(2018).

[64] S. Sinha, A. Raj, Polycyclic aromatic hydrocarbon (PAH) formation from benzyl radicals: a reaction kinetics study, Phys. Chem. Chem. Phys. 18 (2016) 8120-8131.

[65] D.S. Parker, R.I. Kaiser, T.P. Troy, M. Ahmed, Hydrogen abstraction/acetylene addition revealed, Angew. Chem. Int. Edit. 53 (2014) 7740-7744.

[66] S. Bejaoui, X. Mercier, P. Desgroux, E. Therssen, Laser induced fluorescence spectroscopy of aromatic species produced in atmospheric sooting flames using UV and visible excitation wavelengths, Combust. Flame 161 (2014) 2479-2491.

[67] Y. Zhang, L. Wang, P. Liu, B. Guan, H. Ni, Z. Huang, H. Lin, Experimental and kinetic study of the effects of $\mathrm{CO} 2$ and $\mathrm{H} 2 \mathrm{O}$ addition on PAH formation in laminar premixed C2H4/O2/Ar flames, Combust. Flame 192 (2018) 439-451.

[68] P. Liu, Y. Zhang, L. Wang, B. Tian, B. Guan, D. Han, Z. Huang, H. Lin, The chemical mechanism of exhaust gas recirculation on polycyclic aromatic hydrocarbons formation based on LIF measurement, Energ. Fuel. (2018). [69] B. Shukla, M. Koshi, A novel route for PAH growth in HACA based mechanisms, Combust. Flame 159 (2012) 3589-3596.

[70] P. Liu, Z. He, G.-L. Hou, B. Guan, H. Lin, Z. Huang, The Diagnostics of Laser-Induced Fluorescence (LIF) Spectra of PAHs in Flame with TD-DFT: Special Focus on Five-Membered Ring, J. Phys. Chem. A 119 (2015) 13009-13017.

[71] D.S. Parker, F. Zhang, Y.S. Kim, R.I. Kaiser, A. Landera, V.V. Kislov, A.M. Mebel, A. Tielens, Low temperature formation of naphthalene and its role in the synthesis of PAHs (polycyclic aromatic hydrocarbons) in the interstellar medium, P. Natl. Acad. Sci. 109 (2012) 53-58.

[72] A.M. Mebel, A. Landera, R.I. Kaiser, Formation mechanisms of naphthalene and indene: from the interstellar medium to combustion flames, J. Phys. Chem. A 121 (2017) 901-926.

[73] L. Zhao, R.I. Kaiser, B. Xu, U. Ablikim, M. Ahmed, M.V. Zagidullin, V.N. Azyazov, A.H. Howlader, S.F. Wnuk, A.M. Mebel, VUV Photoionization Study of the Formation of the Simplest Polycyclic Aromatic Hydrocarbon: Naphthalene (C10H8), J. Phys. Chem. Lett. 9 (2018) 2620-2626. 


\section{Acknowledgment}

The research was supported by the Clean Combustion Research Center at the King Abdullah University of Science and Technology (KAUST). The work at Shanghai Jiao Tong University was supported by National Natural Science Foundation of China (91441129) and the 111 Project (B13018). 